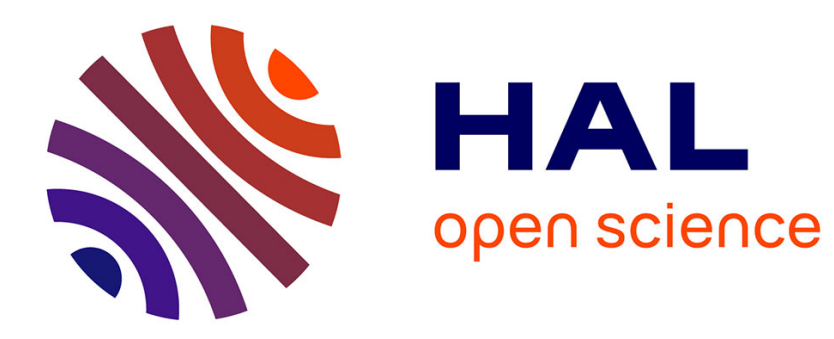

\title{
Ingratiation and Favoritism in Organizations
}

Agnieszka Rusinowska, Vassili Vergopoulos

\section{To cite this version:}

Agnieszka Rusinowska, Vassili Vergopoulos. Ingratiation and Favoritism in Organizations. 2016. halshs-01278060

\section{HAL Id: halshs-01278060 \\ https://shs.hal.science/halshs-01278060}

Submitted on 23 Feb 2016

HAL is a multi-disciplinary open access archive for the deposit and dissemination of scientific research documents, whether they are published or not. The documents may come from teaching and research institutions in France or abroad, or from public or private research centers.
L'archive ouverte pluridisciplinaire HAL, est destinée au dépôt et à la diffusion de documents scientifiques de niveau recherche, publiés ou non, émanant des établissements d'enseignement et de recherche français ou étrangers, des laboratoires publics ou privés. 


\section{Documents de Travail du

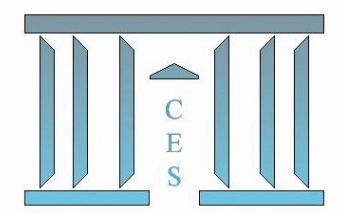

Ingratiation and Favoritism in Organizations

Agnieszka RusinowskA, Vassili Vergopoulos

2016.10

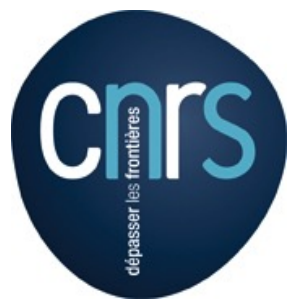

Maison des Sciences Économiques, 106-112 boulevard de L'Hôpital, 75647 Paris Cedex 13 


\title{
Ingratiation and Favoritism in Organizations ${ }^{\star}$
}

\author{
Agnieszka Rusinowska ${ }^{1}$ and Vassili Vergopoulos ${ }^{2}$ \\ 1 Paris School of Economics - CNRS, Université Paris I Panthéon-Sorbonne \\ Centre d'Economie de la Sorbonne, 106-112 Bd de l'Hôpital, 75647 Paris Cedex 13, France \\ Phone: 0033144078 212, Fax: 0033144078301 \\ agnieszka.rusinowska@univ-paris1.fr \\ 2 Paris School of Economics, Université Paris I Panthéon-Sorbonne, Centre d'Economie de la Sorbonne \\ vassili.vergopoulos@univ-paris1.fr
}

\begin{abstract}
We combine in the same theoretical framework two related phenomena that can be present in organizations - ingratiation of subordinates and favoritism of superiors towards some of their employees. There are three actors in the model: a worker, a manager supervising the worker, and a firm that employs the worker and the manager. Ingratiation is defined as a strategic behavior of the worker to make himself more attractive to the manager. In our model ingratiation is expressed by opinion conformity which is exerted by the worker when reporting his opinion to the manager. Favoritism of the manager is based on using a bias when reporting to the firm her observation of the worker's performance. First, we determine the optimal level of the effort and the reported opinion of the worker, and the level of bias of the manager. Then, we investigate the effects of favoritism and ingratiation on the expected wages and utilities of the worker and the manager, and on the expected profit of the firm.
\end{abstract}

JEL Classification: D8, D2, L2, C65

Keywords: ingratiation, opinion conformity, favoritism, organization, performance, wage, profit

Corresponding author: Agnieszka Rusinowska

\section{Introduction}

While traditional research on influence within organizations usually focuses on influence of managers on subordinates, in practice influence of subordinates on managers is also present in organizations. This kind of influence is called ingratiation and can be defined as "a strategic attempt to get someone to like you in order to obtain compliance with a request" (Vaughan and Hogg (2008)) or as "a class of strategic behaviors employed by a person to make himself more attractive to another" (Wortman and Linsenmeier (1977)). Jones (1964) distinguishes three major tactics of ingratiation: opinion conformity, self-presentation, and other-enhancement. Opinion conformity means expressing opinions similar to the one held by a target person. Self-presentation is based on presenting own attributes in a manner that the target would approve and like. Other-enhancement is used to gain compliance by flattering a target or reasoning with him/her instead of forcing compliance.

In the paper we are interested in the first ingratiation tactic that can be used within organizations, i.e., opinion conformity. However, in order to provide a deeper study of

\footnotetext{
* Agnieszka Rusinowska acknowledges the support by the National Agency for Research (Agence Nationale de la Recherche), Project DynaMITE (ANR-13-BSH1-0010-01).
} 
interaction in organizations, we extend the analysis to another closely related phenomenon - favoritism. Clearly, ingratiation may be encouraged by the development of subjective appraisals of subordinates which leads directly to favoritism, where managers act on personal preferences and treat or evaluate some subordinates better than others. The main contribution of the present paper to the existing literature is based on combining ingratiation and favoritism in the same framework. Our point of departure is the model of favoritism presented in Prendergast and Topel (1996), but we extend their framework by introducing the possibility of ingratiation. We are aware of only one work that considers ingratiation and favoritism in the same time, i.e., Robin et al. (2014) who investigate experimentally ingratiatory behavior expressed by opinion conformity. While they also departure from Prendergast and Topel (1996), we present a more general framework and focus on the theoretical investigation of the model of ingratiation and favoritism. Consequently, our analysis provides many insights complementary to those found by the experimental study of Robin et al. (2014).

Although considering together favoritism and ingratiation has not been exploited before, there exists a vast literature that studies each of these two phenomena separately. Concerning favoritism, Prendergast and Topel (1996) examine the conditions under which favoritism is costly to organizations and analyze the effects of favoritism on compensation and the use of bureaucratic rules. A related literature concerns performance evaluation (e.g., Holmstrom and Milgrom (1991); Baker (1992)) and collusion within organizations (e.g., Kofman and Lawarrée (1993); Tirole (1986)). Bandiera et al. (2009) study the effect of social connections between workers and managers on the productivity of workers and on the firm's overall performance. They find that managers who are paid fixed wages favor workers to whom they are socially connected irrespective of the workers' ability. For other works on positive and negative effects of social connections on performance evaluations, job satisfaction and promotions, see, e.g. Podolny and Baron (1997); Thomas (1990); Wesolowski and Mossholder (1997). Levine et al. (2010) analyze the consequences of nepotism or the brother-in-law effect, which means favoring family members, friends and others from whose gratitude the hiring person could benefit. Also Bramoullé and Goyal (2014) study the economic origins and the detrimental consequences of favoritism. They argue that favoritism is a mechanism for surplus diversion away from the society toward one's own social group. Some studies show that in parallel to the detrimental effects there might also exist benefits from favoritism, for instance, facilitating communication when opinion proximity is favored. Efferson et al. (2008) show that in-group favoritism may help heterogeneous individuals to solve coordination problems. There also exist numerous works that show empirical evidence of favoritism in different activities and environments, e.g., in business relations and companies (Gardner (2011)), in sports (Garicano et al. (2005); Kocher and Sutter (2004)), in scientific journals (Laband and Piette (1994)), concerning demographic characteristics (Goldin and Rouse (2000); Knowles et al. (2001)), among others. Another stream of related studies concerns discrimination based on social distance or personal relations, see, e.g., Brandts and Sola (2010); Falk and Zehnder (2013); Filippin and Guala (2013); Zizzo (2011).

The phenomenon of ingratiation is also very broadly examined in several scientific fields and a variety of environments. The experimental and empirical approaches seem to be still leading in these studies. In particular, social psychologists investigate extensively 
ingratiatory and conformity behaviors; see e.g., Asch (1951); Appelbaum and Hughes (1998); Gordon (1996); Higgins et al. (2003). Also economists are strongly interested in the study of conformity. To give some examples, the theory of yes-men by Prendergast (1993) provides a rationale for subordinates to conform to the opinion of their superiors' opinions when firms use subjective performance evaluation. Influence activities and other forms of rent seeking in organizations are also studied in Milgrom (1988); Milgrom and Roberts $(1988,1990)$. There exist various explanations of conformity, like informational deficit, present e.g. in herding behavior (Banerjee (1992); Scharfstein and Stein (1990)) and informational cascades (Bikhchandani et al. (1992)), or the issues of status (Bernheim (1994)) and social norms (Akerlof (1980); Jones (1984)), among others. Also in organizational settings, the empirical evidence and study of influence and ingratiation are of particular interest; see, e.g., Liden and Mitchell (1988), Westphal and Stern (2006).

We analyze these two related phenomena in the same theoretical framework and investigate a model of favoritism and ingratiation. Similarly to Prendergast and Topel (1996) we consider a small organization with a worker, a manager, and a firm. The manager privately observes the worker's performance with the effort as its main component, and she reports this performance to the firm. Also the firm obtains its own private observation of the worker's performance and compares the manager's report with its own observation. These two pieces of information obtained by the firm are used for determining the wages of the worker and the manager. A new element that we introduce in this model is based on expressing opinions, which opens the possibility for the ingratiating behavior of the worker towards the manager and enriches the analysis of favoritism. More precisely, the manager and the worker are assumed to have opinions on a certain issue. The opinions are represented by real numbers which allows us to speak about a distance between two opinions. The worker reports his opinion to the manager after learning that of the manager. The report on the observation of the worker's performance and the report of the opinion can be different from the true values, which leads to the manager's favoritism and the worker's ingratiation. Ingratiation and effort are costly.

We start our analysis by examining the optimal behavior of the worker and the manager. More precisely, we determine the optimal level of the effort and the reported opinion of the worker, and the level of bias in reporting the worker's performance by the manager. The results are fairly intuitive. The bias increases with ingratiation and the impact of the manager's report on pay, but decreases with the price of favoritism. Ingratiation leads to a smaller level of effort and reduces the distance to the manager's opinion. We also investigate the effects of favoritism and ingratiation on the expected wages and utilities of the worker and the manager, and on the expected profit of the firm. The latter is defined as the sum of the worker's effort and his talent minus the wages of the worker and the manager that the firm has to pay. Our results confirm the statement that favoritism and ingratiation are closely related phenomena. In the absence of favoritism, the worker is better off by not ingratiating, while in the absence of ingratiation, favoritism has no effect on the optimal level of the worker's effort. While in the presence of favoritism, ingratiation is detrimental to the manager's wage, it might be beneficial to the worker's wage but only if the penalty for favoritism is sufficiently small. In the presence of favoritism, ingratiation might also increase the profit of the firm but only if the global impact on the worker's pay of the manager's report and of the firm's observation is sufficiently high. It is good for the firm if the manager tries to infer the worker's real opinion. This is also 
good for the manager herself, but it is clearly not beneficial to the worker. If the firm tries to infer the manager's real observation of the performance, then it is better for the firm if the manager also tries to infer the worker's real opinion. Nevertheless, the firm always estimates that under favoritism and ingratiation the firm pays a higher total wage in expectation than what it should have paid.

The remaining part of the paper is structured as follows. In Section 2 we describe formally the model and analyze the optimal behavior of the manager and the worker. In Section 3 we deliver a detailed analysis of the effects of favoritism and ingratiation on the behavior and wages of the worker and the manager, and on the profit of the firm. Concluding remarks are presented in Section 4. The proofs of the crucial equations that support our results are given in Appendix.

\section{The model of ingratiation and favoritism}

\subsection{Description of the model}

Our point of departure is a model of favoritism introduced in Prendergast and Topel (1996). We consider a model with three actors: a worker, a manager supervising the worker, and a firm that employs the worker and the manager. The manager privately observes a nonverifiable measure of the worker's performance given by

$$
y_{m}=e+\alpha+\epsilon_{m}
$$

where $e$ is the level of effort exerted by the worker, $\alpha$ is the worker's talent for the task performed in the company and $\epsilon_{m}$ is measurement error that adds noise to the manager's observation of true performance. It is assumed that $\alpha \rightsquigarrow \mathcal{N}\left(0, \sigma_{\alpha}^{2}\right), \epsilon_{m} \rightsquigarrow \mathcal{N}\left(0, \sigma_{m}^{2}\right)$, and $\epsilon_{m}$ and $\alpha$ are uncorrelated.

Also the firm obtains its own private observation of the worker's performance given by $y_{f}$ where

$$
y_{f}=e+\alpha+\epsilon_{f}
$$

and $\epsilon_{f} \rightsquigarrow \mathcal{N}\left(0, \sigma_{f}^{2}\right)$.

The manager has to report to the firm the worker's performance. We denote her report by $\tilde{y}_{m}$. The manager can exercise favoritism, which means in this framework that she biases the report of the worker's performance. The firm compares the performance $\tilde{y}_{m}$ reported by the manager to its own observation $y_{f}$ of the worker's performance and pays the manager the wage given by

$$
w_{m}=w_{0}-\frac{1}{2} \lambda\left(\tilde{y}_{m}-y_{f}\right)^{2}
$$

where $\lambda>0$ can be interpreted as the price of exercising favoritism or the penalty for perceived bias. The firm pays the worker the wage determined by

$$
w_{w}=\tau_{0}+\tau_{m} \tilde{y}_{m}+\tau_{f} y_{f}
$$

where $\tau_{0}, \tau_{m}, \tau_{f} \in \mathbb{R}^{+}$. In other words, the worker's wage depends linearly on the information on the worker's performance that the firm possesses: the performance reported by the manager and the performance observed by the firm itself. $\tau_{m}$ and $\tau_{f}$ represent the 
impact on the worker's pay of the manager's report and of the firm's own signal of the worker's performance, respectively.

In the present framework we extend the model of favoritism (Prendergast and Topel (1996)) by introducing a possibility of ingratiation expressed by opinion conformity. More precisely, the manager and the worker are assumed to have opinions on a certain issue. Opinions are real numbers in $[0,1]$. Let $\theta \in[0,1]$ denote the actual opinion of the worker, which is assumed to be known only to himself. Let $\theta_{m} \in[0,1]$ denote the opinion of the manager, which will be declared to the worker. After learning the opinion $\theta_{m}$ of the manager, the worker reports to the manager his opinion denoted by $\tilde{\theta} \in[0,1]$. By

$$
d(\theta, \tilde{\theta})=(\theta-\tilde{\theta})^{2}
$$

we denote the distance between the opinions $\theta$ and $\tilde{\theta}$. The worker can exercise ingratiation, meaning that his actual and reported opinions can differ from each other, i.e., it can be that $\tilde{\theta} \neq \theta$. While we do not explicitly assume that under ingratiation $d\left(\tilde{\theta}, \theta_{m}\right)<d\left(\theta, \theta_{m}\right)$ when $\theta \neq \theta_{m}$, it will be shown that under optimal behavior of the worker, ingratiation reduces the distance to the manager's opinion.

The worker's utility ${ }^{1}$ is given by

$$
v_{w}=w_{w}-c(d(\theta, \tilde{\theta}), e)
$$

where $c(d(\theta, \tilde{\theta}), e)$ is the cost of ingratiation and effort given by

$$
c(d(\theta, \tilde{\theta}), e)=c(e)+d(\theta, \tilde{\theta})+d(\theta, \tilde{\theta}) c(e)
$$

$c(e)$ denotes the cost of supplying effort $e$ and is assumed to be twice differentiable, nondecreasing and convex. While in the model of favoritism Prendergast and Topel (1996) consider $c(e)$ in the worker's utility, in our model of ingratiation and favoritism we replace $c(e)$ by $c(d(\theta, \tilde{\theta}), e)$. Note that the global cost $c(d(\theta, \tilde{\theta}), e)$ given in (7) is not just a sum of the cost of effort $c(e)$ and the cost of ingratiation measured by $d(\theta, \tilde{\theta})$. It also contains the third component $d(\theta, \tilde{\theta}) c(e)$ that captures a simple and plausible form of relation between the two costs: ingratiation is more costly under higher level of effort, and the effort is more costly under stronger ingratiatory behavior.

The manager's utility depends on the wages $w_{m}$ and $w_{w}$, and is given by

$$
v_{m}=w_{m}+\eta\left(\tilde{\theta}, \theta_{m}\right) w_{w}
$$

where $\eta\left(\tilde{\theta}, \theta_{m}\right)$ is the intensity of the manager's preference for the worker. $\eta\left(\tilde{\theta}, \theta_{m}\right)$ is known only to the manager and is learned after observing $\tilde{\theta}$. We assume a normal distribution $\eta\left(\tilde{\theta}, \theta_{m}\right) \rightsquigarrow \mathcal{N}\left(m\left(\tilde{\theta}, \theta_{m}\right), \sigma^{2}\left(\tilde{\theta}, \theta_{m}\right)\right)$ with the expectation of $\eta$ denoted by $m$ and its variance by $\sigma$. We take

$$
m\left(\tilde{\theta}, \theta_{m}\right)=1-d\left(\tilde{\theta}, \theta_{m}\right), \sigma^{2}\left(\tilde{\theta}, \theta_{m}\right)=\mathrm{Cst}=\sigma^{2}
$$

\footnotetext{
${ }^{1}$ The worker is assumed to be risk-neutral. We could assume, similarly to Prendergast and Topel (1996), that the worker is risk-averse and has exponential utility given by $v_{w}=-\exp \left\{-\mu\left[w_{w}-c(d(\theta, \tilde{\theta}), e)\right]\right\}$, where $\mu>0$ is the constant rate of absolute risk aversion. Since $\sigma^{2}\left(\tilde{\theta}, \theta_{m}\right)$ is constant as stated later on in (9), this would not change our results.
} 
The value $\eta$ increases in expectation as the difference between $\tilde{\theta}$ and $\theta_{m}$ decreases. Greater values of $\sigma^{2}$ indicate greater potential bias. The three random variables $\epsilon_{m}, \epsilon_{f}$ and $\eta\left(\tilde{\theta}, \theta_{m}\right)$ are independent. Also note that the variance is independent of $\tilde{\theta}$ and $\theta_{m}$.

Timing in the model is the following:

- The firm chooses wage functions $w_{w}$ and $w_{m}$ for the worker and the manager, respectively.

- The manager declares her personal opinion $\theta_{m}$ to the worker.

- The worker chooses simultaneously his level of effort $e$ and reports to the manager his opinion $\tilde{\theta}$.

- The manager learns the reported opinion $\tilde{\theta}$. She observes $\eta\left(\tilde{\theta}, \theta_{m}\right)$ and obtains her own private observation $y_{m}$ on the worker's performance. The firms simultaneously receives its private observation $y_{f}$ on the worker's performance.

- The manager reports $\tilde{y}_{m}$ to the firm.

- The firm pays $w_{w}$ and $w_{m}$ to the worker and the manager, respectively.

\subsection{Behavior of the manager and the worker}

We analyze the optimal behavior of the manager and the worker. First, we examine the manager's situation.

The bias in the manager's report, denoted by $b=b\left(\tilde{\theta}, \theta_{m}, \lambda, \tau_{m}\right)$, is defined as the difference between the manager's report on the worker's performance and her expectation of the signal observed by the firm conditional upon the manager's private information. In other words, we have

$$
\tilde{y}_{m}=\mathbb{E}\left(y_{f} \mid y_{m}, e^{*}\right)+b
$$

where $e^{*}$ is the equilibrium level of effort that the parties know the worker will choose. Similarly as in Prendergast and Topel (1996) we write

$$
\mathbb{E}\left(y_{f} \mid y_{m}, e^{*}\right)=\phi y_{m}+(1-\phi) e^{*}
$$

with $\phi=\sigma_{\alpha}^{2} /\left(\sigma_{\alpha}^{2}+\sigma_{m}^{2}\right)$ being a kind of the "compression" parameter. The firm is monitoring how closely the manager's report corresponds to the firm's observation of the worker's performance. This leads the manager to compressing her evaluation of the worker's performance towards her beliefs on the firm's observation.

The manager maximizes her expected utility conditional on $y_{m}$, i.e., she chooses bias $b$ such that

$$
\max _{b} \mathbb{E}\left(v_{m} \mid y_{m}\right)=\max _{b} \mathbb{E}\left(w_{m}+\eta\left(\tilde{\theta}, \theta_{m}\right) w_{w} \mid y_{m}\right)
$$

which gives

$$
b=\frac{\eta\left(\tilde{\theta}, \theta_{m}\right) \tau_{m}}{\lambda}
$$

Equation (12) shows that bias increases with the manager's preferences for the worker, as given by the value of $\eta$. Consistently with equation (9), the more ingratiation, the higher bias. Moreover, bias increases with the impact of the manager's report $\tau_{m}$ on pay. On the other hand, bias decreases with the price of favoritism $\lambda$. 
Prior to receiving by the firm the manager's report $\tilde{y}_{m}$ and to obtaining its own observation $y_{f}$ on the worker's performance, the expected wage of the manager is equal to

$$
\mathbb{E}\left(w_{m}\right)=w_{0}-\frac{1}{2} \lambda\left(\phi \sigma_{m}^{2}+\sigma_{f}^{2}+\frac{m\left(\tilde{\theta}, \theta_{m}\right)^{2} \tau_{m}^{2}}{\lambda^{2}}+\frac{\sigma^{2} \tau_{m}^{2}}{\lambda^{2}}\right)
$$

Given that the baseline wage for the manager is $w_{0}$, equation (13) shows that the firm charges three different sorts of penalties to the manager:

$-\frac{1}{2} \lambda\left(\phi \sigma_{m}^{2}+\sigma_{f}^{2}\right)$ is a penalty that compensates the inability of the firm to observe the exact level of the worker's effort

- $\frac{m\left(\tilde{\theta}, \theta_{m}\right)^{2} \tau_{m}^{2}}{2 \lambda}$ is a penalty that compensates the fact that the manager exerts favoritism. Without favoritism, $m$ is identically equal to 0 and so is this penalty

$-\frac{\sigma^{2} \tau_{m}^{2}}{2 \lambda}$ is a penalty that compensates, not favoritism itself, but rather the fact that the firm does not know the true value of $\eta$.

Next, we analyze the worker's behavior. The worker maximizes his expected utility, i.e., he chooses $e$ and $\tilde{\theta}$ such that

$$
\max _{e, \tilde{\theta}} \mathbb{E}\left(v_{w}\right)=\max _{e, \tilde{\theta}} \mathbb{E}\left(w_{w}-c(d(\theta, \tilde{\theta}), e)\right)
$$

which gives

$$
c^{\prime}(e)=\frac{\phi \tau_{m}+\tau_{f}}{1+(\tilde{\theta}-\theta)^{2}}
$$

and

$$
\tilde{\theta}=\frac{\frac{\tau_{m}^{2}}{\lambda} \theta_{m}+(1+c(e)) \theta}{\frac{\tau_{m}^{2}}{\lambda}+1+c(e)}
$$

By comparing (14) with the corresponding result of Prendergast and Topel (1996) where the worker chooses effort such that $c^{\prime}(e)=\phi \tau_{m}+\tau_{f}$, we can conclude that the possibility of ingratiation leads to smaller effort. Moreover, the higher the distance $d(\tilde{\theta}, \theta)=(\tilde{\theta}-\theta)^{2}$ between the real and reported opinions of the worker, the smaller the exerted effort. Also (15) has a natural interpretation: ingratiation reduces the distance to the manager's opinion, and the reported opinion of the worker 'lies' between his real opinion and the opinion of the manager. The weights are such that the higher the exerted effort or the price of favoritism, the closer the opinion reported by the worker to his real opinion. Also, the higher the incentive to ingratiate, the closer the reported opinion to the opinion of the manager. Note that the manager does not know the real effort and therefore cannot infer the real opinion from the reported one. But she can learn an estimation of the real opinion by replacing $e$ by $y_{m}$.

In the experimental design of Robin et al. (2014), workers are allowed to change their initial opinion before it is made available to the manager but after receiving a feedback on their performance, differently from our model where the worker chooses simultaneously the level of effort and reports his opinion to the manager. Nevertheless, we can note some similarities between our theoretical results given in (14) and (15), and the experimental evidence obtained in Robin et al. (2014). In particular, Robin et al. (2014) observe that workers with low performance tend to revise their opinion more. This supports their 
behavioral hypothesis that increasing the performance decreases the ingratiation index which measures the worker's ingratiatory behavior. Moreover, Robin et al. (2014) find that many workers report opinions that reduce the distance in opinion with the manager.

\section{Effects of favoritism and ingratiation}

We focus on the impact of favoritism and ingratiation on the behavior and wages of the worker and the manager, and on the profit of the firm being defined as the sum of the effort exerted by the worker and his talent minus the wages paid to the worker and the manager. Formally, the profit of the firm is therefore generically given by

$$
\pi=e^{*}+\alpha-w_{w}-w_{m}=e^{*}+\alpha-\left(\tau_{0}+\tau_{m} \tilde{y}_{m}+\tau_{f} y_{f}\right)-\left(w_{0}-\frac{\lambda}{2}\left(\tilde{y}_{m}-y_{f}\right)^{2}\right)
$$

where $e^{*}$ is the equilibrium level of effort and $\tilde{y}_{m}$ is determined by (10) and (11).

\subsection{Effects of ingratiation in the absence of favoritism}

No favoritism does not mean that the manager reports to the firm what she observes, but rather what she thinks that the firm observes. Formally, the bias becomes $b=0$ and her report is given by $\tilde{y}_{m}=\phi y_{m}+(1-\phi) e^{*}$, consistently with equations (10) and (11).

Suppose first that the worker does not ingratiate, which is formally equivalent to imposing that the worker's reported opinion is equal to his actual opinion, i.e., $\tilde{\theta}=\theta$. Then, the worker chooses the level of effort so as to maximize

$$
\tau_{0}+\tau_{m}\left(\phi y_{m}+(1-\phi) e^{*}\right)+\tau_{f} y_{f}-c(e)-d(\tilde{\theta}, \theta)-c(e) d(\tilde{\theta}, \theta)
$$

Since $\tilde{\theta}=\theta$, the optimal level of effort in the absence of favoritism and ingratiation is given by $c^{\prime}(e)=\phi \tau_{m}+\tau_{f}$.

Suppose now that the worker considers ingratiation. Then, the maximization of (16) leads to the following first-order conditions:

$$
\begin{gathered}
c^{\prime}(e)\left(1+(\tilde{\theta}-\theta)^{2}\right)=\phi \tau_{m}+\tau_{f} \\
\tilde{\theta}=\theta
\end{gathered}
$$

Hence, in the absence of favoritism by the manager, it is systematically suboptimal for the worker to ingratiate. Inserting equation (18) into (17) gives the same level of effort as in the case with no ingratiation. In other words, without favoritism the optimal behavior of the worker is the same, with or without ingratiation. Intuitively, the reason is that ingratiation is costly, while without favoritism it cannot be profitable. We can formulate the following proposition:

Proposition 1 In the absence of favoritism, the possibility of ingratiation has no effect on the optimal behavior of the worker and it is optimal for the worker not to ingratiate.

Let $e^{n f}$ denote the optimal level of effort in the absence of favoritism. Then we have

$$
c^{\prime}\left(e^{n f}\right)=\phi \tau_{m}+\tau_{f}
$$

Let $\pi^{n f}$ denote the profit of the firm in the case of no favoritism. The expected profit of the firm is then equal to

$$
\mathbb{E}\left(\pi^{n f}\right)=e^{n f}\left(1-\tau_{m}-\tau_{f}\right)-\tau_{0}-w_{0}+\frac{\lambda}{2}\left(\phi \sigma_{m}^{2}+\sigma_{f}^{2}\right)
$$




\subsection{Effects of favoritism in the absence of ingratiation}

Next, we assume that favoritism by the manager can be present, but the worker does not ingratiate. As a consequence, the manager biases her report according to equations (10) and (11), and the worker reports his real opinion, i.e., $\widetilde{\theta}=\theta$. Hence, by virtue of (12), the manager's bias is equal to $b=\frac{\eta\left(\theta, \theta_{m}\right) \tau_{m}}{\lambda}$. Moreover, the worker chooses the level of effort so as to maximize

$$
\tau_{0}+\tau_{m}\left(\phi y_{m}+(1-\phi) e^{*}\right)+\tau_{f} y_{f}+\frac{\tau_{m}^{2}}{\lambda} m\left(\theta, \theta_{m}\right)-c(e)-d(\tilde{\theta}, \theta)-c(e) d(\tilde{\theta}, \theta)
$$

Clearly, the solution of this maximization problem is the same as in the previous case with the absence of favoritism, since the two objective functions (16) and (19) only differ by a constant, namely $\frac{\tau_{m}^{2}}{\lambda} m\left(\theta, \theta_{m}\right)$. Therefore, the optimal levels of effort in both cases are the same. We can formulate the following proposition:

Proposition 2 In the absence of ingratiation, favoritism has no effect on the optimal level of effort.

In other words, if $e^{f n i}$ denotes the optimal level of effort under favoritism and in the absence of ingratiation, then we have

$$
c^{\prime}\left(e^{f n i}\right)=c^{\prime}\left(e^{n f}\right)=\phi \tau_{m}+\tau_{f}
$$

While the optimal levels of effort in both cases are the same, what is different is the reported performance being affected by favoritism, i.e., the manager's bias typically increases the reported performance. As a consequences, the wages of the worker and the manager, as well as the profit of the firm change with favoritism.

In order to determine the effects of favoritism, we calculate the expected wage and utility differences for the worker and the firm, and the expected profit of the firm. We get the following:

$$
\begin{gathered}
\mathbb{E}\left(w_{w}^{f n i}-w_{w}^{n f}\right)=\mathbb{E}\left(v_{w}^{f n i}-v_{w}^{n f}\right)=\frac{\tau_{m}^{2}}{\lambda} m\left(\theta, \theta_{m}\right) \geq 0 \\
\mathbb{E}\left(w_{m}^{f n i}-w_{m}^{n f}\right)=-\frac{\tau_{m}^{2}}{2 \lambda}\left(m\left(\theta, \theta_{m}\right)^{2}+\sigma^{2}\right) \leq 0 \\
\mathbb{E}\left(v_{m}^{f n i}-v_{m}^{n f}\right)=\frac{\tau_{m}^{2}}{2 \lambda}\left(m\left(\theta, \theta_{m}\right)^{2}-\sigma^{2}\right) \\
\mathbb{E}\left(\pi^{f n i}\right)=\mathbb{E}\left(\pi^{n f}\right)-\frac{\tau_{m}^{2}}{\lambda}\left(m\left(\theta, \theta_{m}\right)-\frac{m\left(\theta, \theta_{m}\right)^{2}}{2}-\frac{\sigma^{2}}{2}\right)
\end{gathered}
$$

where similarly to the notation used for the effort, the upper index fni refers to the case of favoritism and no ingratiation, and $n f$ corresponds to the case of no favoritism (with or without ingratiation). From (21) we immediately conclude that

Proposition 3 In the absence of ingratiation, favoritism is beneficial to the worker both with respect to the wage and the utility. 
This result has a natural explanation. Given that the optimal level of effort and the reported opinion are the same in both cases and that the manager biases the report of the worker's performance, the worker's wage as well as the utility are higher in the presence of favoritism and the absence of ingratiation. Intuitively, the additional wage due to favoritism increases when the weight $\tau_{m}$ assigned by the firm to the manager's report increases, or when the price $\lambda$ of exerting favoritism decreases, or even when the worker happens to have an opinion closer to the manager's one.

Equations (22) and (23) show that favoritism is always detrimental to the manager's wage, but not necessarily to her utility, since the manager's utility also depends on the worker's wage. Similarly equation (24) leads to the conclusion that the impact of favoritism on the profit of the firm is not uniquely determined. In particular, if $\sigma^{2}>1$, then $\mathbb{E}\left(v_{m}^{f n i}-v_{m}^{n f}\right)<0$ and $\mathbb{E}\left(\pi^{f n i}\right)>\mathbb{E}\left(\pi^{n f}\right)$, i.e., favoritism decreases the manager's utility but is beneficial to the firm. This can be interpreted as follows: a large $\sigma^{2}$ means that the firm perceives much uncertainty about the true values $\eta$ of the coefficient of favoritism and penalizes the manager. More precisely, the third component $\frac{\sigma^{2} \tau_{m}^{2}}{2 \lambda}$ of the penalty in (13) is large enough to ensure $\mathbb{E}\left(\pi^{f n i}\right)>\mathbb{E}\left(\pi^{n f}\right)$. If, in contrast, $\sigma$ is low enough, that is, if standard deviation of the value of the coefficient of favoritism is smaller than its mean value, then the manager is better off when exerting favoritism due to the additional utility she derives from the worker's wage. If $\sigma^{2} \leq 1$, then $\mathbb{E}\left(\pi^{f n i}\right) \geq \mathbb{E}\left(\pi^{n f}\right)$ if and only if $\sqrt{1-\sigma^{2}} \leq\left(\theta-\theta_{m}\right)^{2} \leq 1$. Hence, when the firm perceives sufficiently little uncertainty about the coefficient of favoritism, favoritism becomes beneficial to the firm only when the true opinion of the worker and the opinion of the manager radically differ. On the one hand, due to this radical difference in opinions, the manager has no incentives, at least in expectation, to exert favoritism. The firm still charges a small penalty for its lack of knowledge of the coefficient of favoritism which finally makes favoritism slightly beneficial to the firm. We can summarize these results in the following propositions:

Proposition 4 In the absence of ingratiation, favoritism is never beneficial to the manager's wage.

Proposition 5 In the absence of ingratiation, if the firm perceives sufficiently much uncertainty about the true values of the coefficient of favoritism, then favoritism is not beneficial to the manager's utility but is beneficial to the firm.

\subsection{Effects of ingratiation in the presence of favoritism}

In order to examine the effects of ingratiation in the presence of favoritism, we compare the case of favoritism and ingratiation (denoted by the upper index $f$ ) and the case of favoritism and no ingratiation (denoted by fni). From equation (14), the optimal level of effort $e^{f i}$ under favoritism and ingratiation is given by

$$
c^{\prime}\left(e^{f i}\right)=\frac{\phi \tau_{m}+\tau_{f}}{1+(\tilde{\theta}-\theta)^{2}}
$$

Comparing (25) with equation (20) gives immediately $e^{f i} \leq e^{f n i}$, and therefore we have

Proposition 6 In the presence of favoritism, ingratiation leads to a lower optimal level of effort exerted by the worker. 
For the effect of ingratiation on the worker's wage, we calculate the wage difference in both cases and get:

$$
\mathbb{E}\left(w_{w}^{f i}-w_{w}^{f n i}\right)=\left(\tau_{m}+\tau_{f}\right)\left(e^{f i}-e^{f n i}\right)+\frac{\tau_{m}^{2}}{\lambda}\left(\left(\theta-\theta_{m}\right)^{2}-\left(\tilde{\theta}-\theta_{m}\right)^{2}\right)
$$

Note that the term $\left(\tau_{m}+\tau_{f}\right)\left(e^{f i}-e^{f n i}\right)$ is always nonpositive and represents the loss to the worker generated by ingratiation. Indeed, ingratiation leads the worker to a lower level of effort, and therefore to a smaller value of the signal $y_{f}$ observed by the firm, which induces a lower wage. On the other hand, the term $\frac{\tau_{m}^{2}}{\lambda}\left(\left(\theta-\theta_{m}\right)^{2}-\left(\tilde{\theta}-\theta_{m}\right)^{2}\right)$ is always nonnegative (since by equation (15) ingratiation reduces the distance to the manager's opinion) and represents the gain to the worker. Ingratiation does indeed lead to the manager's over-reporting the worker's performance, and therefore to a higher value of $\tilde{y}_{m}$, which increases the worker's wage. As a result, the global impact of ingratiation on the worker's expected wage can be positive or negative, depending on which of these two effects dominates.

Under a large enough penalty $\lambda$, ingratiation has a negative impact on the worker's expected wage. The negative effect - the fact that the worker puts less effort under ingratiation - is totally independent of $\lambda$. However, large values of $\lambda$ reduce the manager's bias in her report of the worker's performance to the firm, and therefore there is no gain of ingratiation to the worker. For the exactly opposite reasons, sufficiently small values of the penalty make ingratiation always beneficial to the worker.

Concerning the effect of ingratiation on the worker's utility, we get:

$$
\mathbb{E}\left(v_{w}^{f i}-v_{w}^{f n i}\right)=\mathbb{E}\left(w_{w}^{f i}-w_{w}^{f n i}\right)+c\left(e^{f n i}\right)-c\left(e^{f i}\right)-d(\theta, \tilde{\theta})\left(1+c\left(e^{f i}\right)\right)
$$

Similarly as for the worker's wage, the effect of ingratiation on his utility can be positive or negative. In particular, if the worker does not ingratiate "sufficiently", i.e., if $\tilde{\theta}$ is close or even equal to $\theta$, then the effect of ingratiation on the worker's utility is more positive (or less negative) than the effect on his wage. We can write the following proposition:

Proposition 7 In the presence of favoritism, ingratiation is detrimental to the worker's expected wage if the penalty for favoritism is sufficiently high, and it is beneficial if this penalty is sufficiently small.

In order to elaborate more on the effect of ingratiation on the worker's situation, consider the case where $c(e)=\frac{1}{2} e^{2}$. Then, from (20) and (25), equation (26) becomes:

$$
\mathbb{E}\left(w_{w}^{f i}-w_{w}^{f n i}\right)=\frac{\tau_{m}^{2}}{\lambda}\left(\left(\theta-\theta_{m}\right)^{2}-\left(\tilde{\theta}-\theta_{m}\right)^{2}\right)-\left(\tau_{m}+\tau_{f}\right)\left(\phi \tau_{m}+\tau_{f}\right)\left(\frac{(\tilde{\theta}-\theta)^{2}}{1+(\tilde{\theta}-\theta)^{2}}\right)
$$

Obviously, if the worker has the same opinion as the manager, the possibility of ingratiation does not affect the worker's expected wage.

Suppose now that the worker and the manager have radically different opinions. Without loss of generality, we can assume that their opinions are respectively given by $\theta=0$ and $\theta_{m}=1$. Then:

$$
\mathbb{E}\left(w_{w}^{f i}-w_{w}^{f n i}\right)=\frac{\tau_{m}^{2}}{\lambda} \tilde{\theta}(2-\tilde{\theta})-\left(\tau_{m}+\tau_{f}\right)\left(\phi \tau_{m}+\tau_{f}\right) \frac{\tilde{\theta}^{2}}{1+\tilde{\theta}^{2}}
$$


A sufficient condition for $\mathbb{E}\left(w_{w}^{f i}-w_{w}^{f n i}\right)$ to be positive is then

$$
\frac{\tau_{m}^{2}}{\lambda} \geq\left(\tau_{m}+\tau_{f}\right)\left(\phi \tau_{m}+\tau_{f}\right)
$$

(28) is typically satisfied for sufficiently small values of $\tau_{f}$, which represents the impact of the firm's own signal on the worker's pay. Moreover, (28) can be equivalently written as

$$
\left(\frac{1}{\lambda}-\phi\right) \tau_{m}^{2}-(\phi+1) \tau_{f} \tau_{m}-\tau_{f}^{2} \geq 0
$$

which is also typically satisfied whenever $\phi \lambda \leq 1$, the impact $\tau_{m}$ of the manager's report on the worker's pay is sufficiently large, and the weight $\phi$ in the manager's report that is assigned to her own observation is relatively low, even in the case of a large $\lambda$.

Concerning the effect of ingratiation on the manager's wage, equation (13) leads to

$$
\begin{gathered}
\mathbb{E}\left(w_{m}^{f i}-w_{m}^{f n i}\right)=\frac{\tau_{m}^{2}}{2 \lambda}\left(m\left(\theta, \theta_{m}\right)^{2}-m\left(\tilde{\theta}, \theta_{m}\right)^{2}\right)= \\
=\frac{\tau_{m}^{2}}{2 \lambda}\left(\left(\tilde{\theta}-\theta_{m}\right)^{2}-\left(\theta-\theta_{m}\right)^{2}\right)\left(2-\left(\tilde{\theta}-\theta_{m}\right)^{2}-\left(\theta-\theta_{m}\right)^{2}\right) \leq 0
\end{gathered}
$$

On the one hand, the term $\left(\tilde{\theta}-\theta_{m}\right)^{2}-\left(\theta-\theta_{m}\right)^{2}$ is always negative, since by virtue of equation (15) ingratiation reduces the distance between opinions. On the other hand, the term $\left(2-\left(\tilde{\theta}-\theta_{m}\right)^{2}-\left(\theta-\theta_{m}\right)^{2}\right)$ is positive since opinions lie in the unit interval of the real numbers. Hence, in the presence of ingratiation, the firm pays less to the manager. The reason lies in the decomposition of the penalty given in (13). The second component of this penalty, which is the price of favoritism, increases and the manager gets a smaller wage. Next, we compute $\mathbb{E}\left(v_{m}^{f i}-v_{m}^{f n i}\right)$ and get

$$
\begin{gathered}
\mathbb{E}\left(v_{m}^{f i}-v_{m}^{f n i}\right)=\frac{\tau_{m}^{2}}{2 \lambda}\left(m\left(\tilde{\theta}, \theta_{m}\right)^{2}-m\left(\theta, \theta_{m}\right)^{2}\right)+ \\
+m\left(\tilde{\theta}, \theta_{m}\right)\left(\tau_{0}+\left(\tau_{m}+\tau_{f}\right) e^{f i}\right)-m\left(\theta, \theta_{m}\right)\left(\tau_{0}+\left(\tau_{m}+\tau_{f}\right) e^{f n i}\right)
\end{gathered}
$$

which can be positive or negative. Since the utility of the manager depends both on her wage and the wage of the worker, ingratiation can increase the manager's utility contrary to her wage. We write the following proposition:

Proposition 8 In the presence of favoritism, ingratiation decreases the manager's wage, but can have positive effect on the manager's utility.

Finally, concerning the effect of ingratiation on the firm's expected profit, by using (26) and (29) we get

$$
\mathbb{E}\left(\pi^{f i}\right)=\mathbb{E}\left(\pi^{f n i}\right)+\left(1-\tau_{m}-\tau_{f}\right)\left(e^{f i}-e^{f n i}\right)+\frac{\tau_{m}^{2}}{2 \lambda}\left(\left(\tilde{\theta}-\theta_{m}\right)^{4}-\left(\theta-\theta_{m}\right)^{4}\right)
$$

The difference in expected profit that is due to the possibility of ingratiation can be both positive and negative. The second term $\frac{\tau_{m}^{2}}{2 \lambda}\left(\left(\tilde{\theta}-\theta_{m}\right)^{4}-\left(\theta-\theta_{m}\right)^{4}\right)$ in equation (31) is always negative since ingratiation reduces the distance between opinions. In the 
case where the impacts on the worker's pay of the manager's report and of the firm's observation are low, that is, $\tau_{m}+\tau_{f} \leq 1$, the first component $\left(1-\tau_{m}-\tau_{f}\right)\left(e^{f i}-e^{f n i}\right)$ is nonpositive, since ingratiation leads the worker to make less effort. As a result, in such a case ingratiation is detrimental to the firm. However, in the case where the sum $\left(\tau_{m}+\tau_{f}\right)$ is sufficiently large, ingratiation becomes beneficial to the firm: since $\tau_{m}+\tau_{f}$ is large, the reduction of effort due to ingratiation implies a big reduction of the worker's wage. We can therefore conclude that

Proposition 9 In the presence of favoritism, ingratiation increases the firm's profit if the global impact on the worker's pay of the manager's report and of the firm's observation is sufficiently high. On the contrary, if this impact is sufficiently low, ingratiation has negative effect on the firm's profit.

\subsection{Inferring the real opinion}

Under favoritism and ingratiation the manager observes $y_{m}^{f i}$ and $\tilde{\theta}$, but she also knows that $\tilde{\theta}$ depends on $\theta$ through equation (15). Let $\bar{\theta}$ denote what the manager thinks is the real opinion of the worker, as a function of $y_{m}^{f i}$ and $\tilde{\theta}$. It is given, by assumption, by the following formula:

$$
\tilde{\theta}=\frac{\frac{\tau_{m}^{2}}{\lambda} \theta_{m}+\left(1+c\left(y_{m}^{f i}\right)\right) \bar{\theta}}{\frac{\tau_{m}^{2}}{\lambda}+1+c\left(y_{m}^{f i}\right)}
$$

or equivalently by

$$
\bar{\theta}=\tilde{\theta}+\frac{\tau_{m}^{2}}{\lambda} \frac{\tilde{\theta}-\theta_{m}}{1+c\left(y_{m}^{f i}\right)}
$$

To illustrate (32), assume that $\theta_{m}=0.1$ and $\tilde{\theta}=0.5$. Then, the manager considers that the true opinion of the worker must be above 0.5 and has to correct $\tilde{\theta}$ by adding a positive term $\frac{\tau_{m}^{2}}{\lambda} \frac{\tilde{\theta}-\theta_{m}}{1+c\left(y_{m}^{f i}\right)}$. Note also that the higher $y_{m}^{f i}$, which means roughly that the worker makes more effort, the smaller this additional term. Moreover, as the impact of the manager's report on the worker's pay increases (i.e., $\tau_{m}$ increases), it becomes more profitable for the worker to ingratiate, and therefore the correction term in (32) becomes larger. Finally, the higher the penalty of favoritism, the lower favoritism, the lower ingratiation, and therefore the term in question is smaller.

It is assumed that the worker is not aware of the fact that the manager tries to infer his real opinion from the reported opinion. Hence, the optimal level of effort is the same as in the "standard" case of favoritism and ingratiation examined in the previous subsection. To simplify the notation, we will use the upper index $f i$ as before whenever trying to infer the real opinion does not change an optimal level (e.g., of the effort). Otherwise, if trying to infer the real opinion changes an optimal level (e.g., of the reported performance), we will use the upper index fi . Using this notation, we get

$$
\mathbb{E}\left(w_{w}^{f i \theta}-w_{w}^{f i}\right)=-\frac{\tau_{m}^{4}}{\lambda^{2}} \frac{\left(\theta_{m}-\tilde{\theta}\right)^{2}}{1+c\left(y_{m}^{f i}\right)}\left(2+\frac{\tau_{m}^{2}}{\lambda} \frac{1}{1+c\left(y_{m}^{f i}\right)}\right) \leq 0
$$

The intuition of this result is clear. Since the manager always corrects the reported opinion by "increasing" the distance to his own opinion, the worker's wage will decrease. 
This is consistent with the empirical evidence found in Robin et al. (2014) that the manager becoming aware of the possibility of ingratiation puts a smaller weight of opinion proximity in the assignment of the worker's payoff. From (33) we can write the following proposition.

Proposition 10 Under favoritism and ingratiation it is detrimental to the worker's wage when the manager tries to infer the worker's real opinion.

Concerning the impact on the manager's wage, using equation (13) we get immediately

$$
\mathbb{E}\left(w_{m}^{f i \theta}-w_{m}^{f i}\right)=\frac{\tau_{m}^{2}}{2 \lambda}\left(m\left(\tilde{\theta}, \theta_{m}\right)^{2}-m\left(\bar{\theta}, \theta_{m}\right)^{2}\right) \geq 0
$$

For the impact on the profit of the firm, we have

$$
\mathbb{E}\left(\pi^{f i \theta}\right)=\mathbb{E}\left(\pi^{f i}\right)-\frac{\tau_{m}^{2}}{2 \lambda}\left(\left(\tilde{\theta}-\theta_{m}\right)^{2}-\left(\bar{\theta}-\theta_{m}\right)^{2}\right)\left(\left(\tilde{\theta}-\theta_{m}\right)^{2}+\left(\bar{\theta}-\theta_{m}\right)^{2}\right) \geq \mathbb{E}\left(\pi^{f i}\right)
$$

Hence, we can write

Proposition 11 Under favoritism and ingratiation it is always beneficial to the manager's wage and the firm's profit when the manager tries to infer the worker's real opinion.

\subsection{Inferring the real observation of the performance}

In the following two subsections we focus on the analysis from the firm's point of view. First, suppose that the firm directly observes the manager's opinion $\theta_{m}$ and the worker's reported opinion $\tilde{\theta}$, and it tries to infer the manager's real observation $y_{m}^{f i}$ of the worker's performance under favoritism and ingratiation. We also assume that the manager does not try to infer the real opinion $\theta$ of the worker. Let $\bar{y}_{m}$ denote what the firm thinks is the real observation $y_{m}^{f i}$ of the manager, as a function of $\tilde{\theta}, \theta_{m}$ and $\tilde{y}_{m}^{f i}$. Then, assuming that the firm estimates the coefficient of favoritism $\eta\left(\tilde{\theta}, \theta_{m}\right)$ as equal to its mean $m\left(\tilde{\theta}, \theta_{m}\right)$, and consistently with (10) and (11), $\bar{y}_{m}$ is implicitly given by:

$$
\tilde{y}_{m}^{f i}=\phi \bar{y}_{m}+(1-\phi) y_{f}^{f i}+\frac{\tau_{m} m\left(\tilde{\theta}, \theta_{m}\right)}{\lambda}
$$

or equivalently

$$
\bar{y}_{m}=\tilde{y}_{m}^{f i}+\frac{1-\phi}{\phi}\left(\tilde{y}_{m}^{f i}-y_{f}^{f i}\right)-\frac{\tau_{m} m\left(\tilde{\theta}, \theta_{m}\right)}{\phi \lambda}
$$

This means that the firm systematically reduces the manager's report by withdrawing from it the quantity $\frac{\tau_{m} m\left(\tilde{\theta}, \theta_{m}\right)}{\phi \lambda}$. Note that, when the price $\lambda$ of exercising favoritism increases, it becomes more costly for the manager to exercise favoritism. Hence, consistently with equation (12) the bias decreases and as a consequence the firm withdraws a smaller quantity $\frac{\tau_{m} m\left(\tilde{\theta}, \theta_{m}\right)}{\phi \lambda}$ from the manager's report. Moreover, higher values of the impact of the manager's report on the worker's pay, as measured by $\tau_{m}$, provide more incentives for the worker to ingratiate as suggested by equation (15). Hence, by equation (12) the manager's bias in her report increases, which explains why the quantity $\frac{\tau_{m} m\left(\tilde{\theta}, \theta_{m}\right)}{\phi \lambda}$ needs to be higher. 
Note that in the particular case where $\phi=1$, equation (36) reduces to $\bar{y}_{m}=\tilde{y}_{m}^{f i}-b$. Then, consistently with equations (10) and (11) we get $\bar{y}_{m}=y_{m}^{f i}$, which means that the firm's estimation of the manager's report is exact. In contrast, when $\phi$ has a very small value, the manager's report on the worker's performance is almost independent of $y_{m}^{f i}$. Hence, there is no real reason why the firm should infer the real $y_{m}^{f i}$.

Eventually, the firm readjusts this reduction by adding a term that is proportional to $\left(\tilde{y}_{m}^{f i}-y_{f}^{f i}\right)$. Hence, if the manager over-reports the worker's performance relatively to the firm's observation (i.e., if $\tilde{y}_{m}^{f i}>y_{f}^{f i}$ ), then the firm compensates this by adding a positive term to the manager's report. However, if the manager under-reports the worker's performance, then the firm further reduces her report. Hence, on the one hand the firm systematically reduces the manager's report, but on the other hand it readjusts its estimation if it finds that the manager over-reports.

Given the firm's estimate $\bar{y}_{m}$, what is (according to the firm) its loss generated by favoritism and ingratiation? First, we consider the worker. The firm effectively pays him $\tau_{0}+\tau_{m} \tilde{y}_{m}^{f i}+\tau_{f} y_{f}^{f i}$. However, the firm considers that it should have paid only $\tau_{0}+\tau_{m} \bar{y}_{m}+$ $\tau_{f} y_{f}^{f i}$. Consequently, what the firm thinks to be the additional wage that is paid to the worker due to favoritism and ingratiation, i.e., the firm's loss with respect to the worker's wage, or equivalently the worker's gain with respect to his wage, is given by

$$
L_{f w}=\left(\tau_{0}+\tau_{m} \tilde{y}_{m}^{f i}+\tau_{f} y_{f}^{f i}\right)-\left(\tau_{0}+\tau_{m} \bar{y}_{m}+\tau_{f} y_{f}^{f i}\right)=\tau_{m}\left(\tilde{y}_{m}^{f i}-\bar{y}_{m}\right)
$$

and the expected loss of the firm is equal to

$$
\mathbb{E}\left(L_{f w}\right)=\frac{\tau_{m}^{2} m\left(\tilde{\theta}, \theta_{m}\right)}{\lambda} \geq 0
$$

Concerning the manager's wage, the firm effectively pays her $w_{0}-\frac{1}{2} \lambda\left(\tilde{y}_{m}^{f i}-y_{f}^{f i}\right)^{2}$. However, it considers that it should have paid only $w_{0}-\frac{1}{2} \lambda\left(\bar{y}_{m}-y_{f}^{f i}\right)^{2}$. Consequently, according to the firm the additional wage that is paid to the manager due to favoritism and ingratiation, i.e., the firm's loss with respect to the manager's wage, or equivalently the manager's gain with respect to her wage, is given by

$L_{f m}=\left(w_{0}-\frac{1}{2} \lambda\left(\tilde{y}_{m}^{f i}-y_{f}^{f i}\right)^{2}\right)-\left(w_{0}-\frac{1}{2} \lambda\left(\bar{y}_{m}-y_{f}^{f i}\right)^{2}\right)=\frac{\lambda}{2}\left(\left(\bar{y}_{m}-y_{f}^{f i}\right)^{2}-\left(\tilde{y}_{m}^{f i}-y_{f}^{f i}\right)^{2}\right)$

and the expected loss of the firm is equal to

$$
\mathbb{E}\left(L_{f m}\right)=\frac{\lambda\left(1-\phi^{2}\right)}{2 \phi^{2}}\left(\phi \sigma_{m}^{2}+\sigma_{f}^{2}+\frac{\sigma^{2} \tau_{m}^{2}}{\lambda^{2}}\right)-\frac{\tau_{m}^{2}}{2 \lambda} m\left(\tilde{\theta}, \theta_{m}\right)^{2}
$$

To interpret equation (38), we recall the interpretation of equation (13). If the firm paid what it considers it should have paid to the manager, then the firm would have lost the penalty that it charges to the manager for exercising favoritism. This explains the fact that the term $-\frac{\tau_{m}^{2}}{2 \lambda} m\left(\tilde{\theta}, \theta_{m}\right)^{2}$ actually represents a gain. In contrast, the term $\frac{\lambda\left(1-\phi^{2}\right)}{2 \phi^{2}}\left(\phi \sigma_{m}^{2}+\sigma_{f}^{2}+\frac{\sigma^{2} \tau_{m}^{2}}{\lambda^{2}}\right)$ represents a real loss of the firm which reflects two kinds of penalties: the one that compensates the inability of the firm to observe the exact level of 
the worker's effort and talent, and the one that compensates the fact that the firm does not know the true value of the coefficient $\eta$ of favoritism.

Finally, we compute the expected aggregate loss of the firm

$$
\mathbb{E}\left(L_{f}\right)=\mathbb{E}\left(L_{f w}\right)+\mathbb{E}\left(L_{f m}\right)
$$

and get

$$
\mathbb{E}\left(L_{f}\right)=\frac{\lambda\left(1-\phi^{2}\right)}{2 \phi^{2}}\left(\phi \sigma_{m}^{2}+\sigma_{f}^{2}+\frac{\sigma^{2} \tau_{m}^{2}}{\lambda^{2}}\right)+\frac{\tau_{m}^{2} m\left(\tilde{\theta}, \theta_{m}\right)}{\lambda}\left(1-\frac{1}{2} m\left(\tilde{\theta}, \theta_{m}\right)\right) \geq 0
$$

Hence, we can write the following proposition:

Proposition 12 If the manager does not try to infer the worker's real opinion but the firm tries to infer the manager's real observation of the worker's performance, then the firm estimates that favoritism and ingratiation make it pay a higher wage in expectation to the worker and a higher total wage in expectation to the worker and the manager than what it should have paid.

\subsection{Inferring the real opinion and the real observation of the performance}

Next we assume that, additionally to the fact that the firm tries to infer the manager's real observation of the worker's performance, also the manager tries to infer the real opinion of the worker. The firm knows that the manager tries to infer real $\theta$. Let $\hat{L}_{f w}$ denote the firm's loss with respect to the worker's wage in this case. Then the expected loss of the firm is equal to

$$
\mathbb{E}\left(\hat{L}_{f w}\right)=\frac{\tau_{m}^{2}}{\lambda} m\left(\bar{\theta}, \theta_{m}\right) \geq 0
$$

where $\bar{\theta}$ is given in (32). When comparing this loss with the previous case presented in Section 3.5, where the manager does not try to infer the real opinion (see (37)), we get

$$
\mathbb{E}\left(\hat{L}_{f w}\right)-\mathbb{E}\left(L_{f w}\right)=\frac{\tau_{m}^{2}}{\lambda}\left(\left(\tilde{\theta}-\theta_{m}\right)^{2}-\left(\bar{\theta}-\theta_{m}\right)^{2}\right) \leq 0
$$

Next, let $\hat{L}_{f m}$ denote the loss of the firm with respect to the manager's wage in the considered case. We have

$$
\mathbb{E}\left(\hat{L}_{f m}\right)=\frac{\lambda\left(1-\phi^{2}\right)}{2 \phi^{2}}\left(\phi \sigma_{m}^{2}+\sigma_{f}^{2}+\frac{\sigma^{2} \tau_{m}^{2}}{\lambda^{2}}\right)-\frac{\tau_{m}^{2}}{2 \lambda} m\left(\bar{\theta}, \theta_{m}\right)^{2}
$$

and when comparing this loss with the previous case analyzed in Section 3.5 (see (38)), we have

$$
\mathbb{E}\left(\hat{L}_{f m}\right)-\mathbb{E}\left(L_{f m}\right)=\frac{\tau_{m}^{2}}{2 \lambda}\left(\left(\bar{\theta}-\theta_{m}\right)^{2}-\left(\tilde{\theta}-\theta_{m}\right)^{2}\right)\left(2-\left(\bar{\theta}-\theta_{m}\right)^{2}-\left(\tilde{\theta}-\theta_{m}\right)^{2}\right) \geq 0
$$

Finally, concerning the aggregated level of the loss of the firm with respect to both wages that it pays, i.e.,

$$
\mathbb{E}\left(\hat{L}_{f}\right)=\mathbb{E}\left(\hat{L}_{f w}\right)+\mathbb{E}\left(\hat{L}_{f m}\right)
$$


we get

$$
\mathbb{E}\left(\hat{L}_{f}\right)=\frac{\lambda\left(1-\phi^{2}\right)}{2 \phi^{2}}\left(\phi \sigma_{m}^{2}+\sigma_{f}^{2}+\frac{\sigma^{2} \tau_{m}^{2}}{\lambda^{2}}\right)-\frac{\tau_{m}^{2}}{2 \lambda} m\left(\bar{\theta}, \theta_{m}\right)^{2}+\frac{\tau_{m}^{2}}{\lambda} m\left(\bar{\theta}, \theta_{m}\right) \geq 0
$$

Comparing the loss with the one given in (39) gives

$$
\mathbb{E}\left(\hat{L}_{f}\right)-\mathbb{E}\left(L_{f}\right)=\frac{\tau_{m}^{2}}{\lambda}\left(m\left(\bar{\theta}, \theta_{m}\right)-m\left(\tilde{\theta}, \theta_{m}\right)\right)\left(1-\frac{1}{2}\left(m\left(\bar{\theta}, \theta_{m}\right)+m\left(\tilde{\theta}, \theta_{m}\right)\right)\right) \leq 0
$$

By virtue of (43) we can conclude that

Proposition 13 If the firm tries to infer the manager's real observation of the worker's performance, then in terms of the estimated loss of the firm with respect to the manager's wage it is worse for the firm when the manager tries to infer the real opinion of the worker.

Moreover, (41) and (45) lead to

Proposition 14 If the firm tries to infer the manager's real observation of the worker's performance, then in terms of the estimated loss of the firm with respect to the worker's wage and with respect to both wages, it is better for the firm when the manager tries to infer the real opinion of the worker. Nevertheless, the firm still estimates that favoritism and ingratiation make it pay in expectation a higher wage to the worker and a higher total wage than what it should have paid.

\section{Concluding remarks}

Our results on favoritism and ingratiation modeled in the same theoretical framework confirm that these two phenomena are closely related. We show that the effects of one of the phenomena can be related to the presence/absence of the another one. While many studies show the empirical evidence of favoritism and ingratiation separately, we examine if exerting one phenomenon is optimal when the another one is absent. For example, if the manager does not favor workers, then it is better to the workers not to ingratiate at all, since ingratiation is costly and gives no advantage. On the other hand, if the worker does not ingratiate, then whether the manager favor workers or not does not change the optimal level of the effort exerted by the worker.

Bandiera et al. (2009) find that favoritism is detrimental to the firm's overall performance. We can draw a somewhat similar conclusion for the firm, since it estimates that under favoritism and ingratiation the firm always pays a higher total wage than what it should have paid. A message for the firm is that it should hire 'clever' managers who do not lead themselves to be easily ingratiated, since it is always good for the firm to have the manager who tries to infer the worker's real opinion. Bramoullé and Goyal (2014) show that favoritism always reduces aggregate social welfare. In our framework we find some positive effects on the utilities. For instance, when ingratiation is absent, favoritism is beneficial to the worker's utility. When favoritism is present, ingratiation can be beneficial to the manager's utility. Prendergast and Topel (1996) point out that favoritism 
generates value for managers who exercise favoritism, as they derive utility from exercising bias. We can argue in a similar way in our framework, which is not surprising since the favoritism part of our model is similar to the one given in Prendergast and Topel (1996). However, we can also observe a similar effect of ingratiation when considering workers who exercise ingratiatory behavior.

Most of the works on favoritism point out mainly its detrimental effects. Our results are of two natures. On the one hand we show clearly negative effects, like for example the effect of ingratiation on the manager's wage. On the other hand, we can also observe beneficial effects, and some of them are less obvious and not that intuitive. For instance, ingratiation is not always beneficial to the worker's wage and its positive effect is related to favoritism itself, i.e., if the penalty for favoritism is sufficiently small. This confirms only partially the evidence obtained in social psychology of the effect of ingratiation on salary increases and carrier success, also confirmed in Robin et al. (2014). Another message for the firm is that ingratiation might also increase its profit. Nevertheless, it will be the case only if (in particular) the impact on the worker's pay of the firm's observation is sufficiently high. In other words, it seems that the firm might benefit from ingratiation, but it should be sufficiently careful and take largely into account its own observation when setting the worker's wage.

\section{Appendix}

\section{Proof of equation (12)}

Suppose that the worker reports $\tilde{\theta}$. The manager observes $y_{m}$ (which depends on the level of effort chosen by the worker). It is assumed that $\mathbb{E}\left(\epsilon_{m} \mid y_{m}\right)=\mathbb{E}\left(\epsilon_{f} \mid y_{m}\right)=0$ and $\mathbb{E}\left(e \mid y_{m}\right)=y_{m}$. The manager maximizes her expected utility conditional on $y_{m}$, i.e., she chooses $b$ that maximizes

$$
\mathbb{E}\left(w_{m}+\eta\left(\tilde{\theta}, \theta_{m}\right) w_{w} \mid y_{m}\right)=\mathbb{E}\left(w_{0}-\frac{1}{2} \lambda\left(\tilde{y}_{m}-y_{f}\right)^{2}+\eta\left(\tilde{\theta}, \theta_{m}\right) w_{w} \mid y_{m}\right)
$$

We have

$$
\begin{aligned}
\mathbb{E}\left(\left(\tilde{y}_{m}-y_{f}\right)^{2} \mid y_{m}\right) & =\mathbb{E}\left(\left(b+\phi y_{m}+(1-\phi) e^{*}-y_{f}\right)^{2} \mid y_{m}\right) \\
& =\mathbb{E}\left(\left(\phi\left(y_{m}-y_{f}\right)+(1-\phi)\left(e^{*}-y_{f}\right)+b\right)^{2} \mid y_{m}\right) \\
& =\phi^{2} \mathbb{E}\left(\left(y_{m}-y_{f}\right)^{2} \mid y_{m}\right)+(1-\phi)^{2} \mathbb{E}\left(\left(e^{*}-y_{f}\right)^{2} \mid y_{m}\right)+b^{2}+ \\
& +2 \phi(1-\phi) \mathbb{E}\left(\left(y_{m}-y_{f}\right)\left(e^{*}-y_{f}\right) \mid y_{m}\right)+ \\
& +2 b \phi \mathbb{E}\left(y_{m}-y_{f} \mid y_{m}\right)+2 b(1-\phi) \mathbb{E}\left(e^{*}-y_{f} \mid y_{m}\right) \\
= & \phi^{2}\left(\sigma_{m}^{2}+\sigma_{f}^{2}\right)+(1-\phi)^{2}\left(\sigma_{\alpha}^{2}+\sigma_{f}^{2}\right)+b^{2}+2 \phi(1-\phi) \sigma_{f}^{2} \\
\mathbb{E}\left(w_{w} \mid y_{m}\right) & =\mathbb{E}\left(\tau_{0}+\tau_{m} \tilde{y}_{m}+\tau_{f} y_{f} \mid y_{m}\right) \\
& =\mathbb{E}\left(\tau_{0}+\tau_{m}\left(b+\phi y_{m}+(1-\phi) e^{*}\right)+\tau_{f} y_{f} \mid y_{m}\right) \\
& =\tau_{0}+\tau_{m}\left(b+\phi y_{m}+(1-\phi) e^{*}\right)+\tau_{f} \mathbb{E}\left(y_{f} \mid y_{m}\right) \\
& =\tau_{0}+\tau_{m}\left(b+\phi y_{m}+(1-\phi) e^{*}\right)+\tau_{f} y_{m}
\end{aligned}
$$


Hence, the objective function becomes

$$
\begin{aligned}
w_{0} & -\frac{\lambda}{2}\left(\phi^{2}\left(\sigma_{m}^{2}+\sigma_{f}^{2}\right)+(1-\phi)^{2}\left(\sigma_{\alpha}^{2}+\sigma_{f}^{2}\right)+b^{2}+2 \phi(1-\phi) \sigma_{f}^{2}\right) \\
& +\eta\left(\tilde{\theta}, \theta_{m}\right)\left(\tau_{0}+\tau_{m}\left(b+\phi y_{m}+(1-\phi) e^{*}\right)+\tau_{f} y_{m}\right)
\end{aligned}
$$

and from FOC: $-\lambda b+\eta\left(\tilde{\theta}, \theta_{m}\right) \tau_{m}=0$, which gives $b=\frac{\eta\left(\tilde{\theta}, \theta_{m}\right) \tau_{m}}{\lambda}$, i.e., (12).

\section{Proof of equation (13)}

Using equations (1), (2), (10), (11) and (12), we have

$$
\begin{aligned}
\mathbb{E}\left(w_{m}\right) & =w_{0}-\frac{1}{2} \lambda \mathbb{E}\left(\left(\tilde{y}_{m}-y_{f}\right)^{2}\right) \\
& =w_{0}-\frac{1}{2} \lambda \mathbb{E}\left(\left(\phi y_{m}+(1-\phi) e^{*}+\frac{\eta\left(\tilde{\theta}, \theta_{m}\right) \tau_{m}}{\lambda}-y_{f}\right)^{2}\right) \\
& =w_{0}-\frac{1}{2} \lambda \mathbb{E}\left[\left((\phi-1) \alpha+\phi \epsilon_{m}-\epsilon_{f}+\frac{\eta\left(\tilde{\theta}, \theta_{m}\right) \tau_{m}}{\lambda}\right)^{2}\right] \\
& =w_{0}-\frac{1}{2} \lambda\left((\phi-1)^{2} \sigma_{\alpha}^{2}+\phi^{2} \sigma_{m}^{2}+\sigma_{f}^{2}+\frac{\tau_{m}^{2} \sigma^{2}}{\lambda^{2}}+\frac{\tau_{m}^{2} m\left(\tilde{\theta}, \theta_{m}\right)^{2}}{\lambda^{2}}\right)
\end{aligned}
$$

Furthermore, note that $(\phi-1)^{2} \sigma_{\alpha}^{2}+\phi^{2} \sigma_{m}^{2}=\phi \sigma_{m}^{2}$, which finally yields equation (13).

\section{Proof of equations (14) and (15)}

When maximizing his expected utility, the worker anticipates that if he reports $\tilde{\theta}$ and if the manager observes $y_{m}$, then the manager is going to report $\tilde{y}_{m}$ as given by equations (10), (11) and (12). But the worker only knows the normal distribution of $\eta\left(\tilde{\theta}, \theta_{m}\right)$ given in (9). We first compute the wage $w_{w}$ of the worker:

$$
\begin{aligned}
w_{w} & =\tau_{0}+\tau_{m} \tilde{y}_{m}+\tau_{f} y_{f}=\tau_{0}+\tau_{m} \phi y_{m}+\tau_{m}(1-\phi) e^{*}+\frac{\tau_{m}^{2} \eta\left(\tilde{\theta}, \theta_{m}\right)}{\lambda}+\tau_{f} y_{f} \\
& =\tau_{0}+\tau_{m} \phi\left(e+\alpha+\epsilon_{m}\right)+\tau_{m}(1-\phi) e^{*}+\frac{\tau_{m}^{2} \eta\left(\tilde{\theta}, \theta_{m}\right)}{\lambda}+\tau_{f}\left(e+\alpha+\epsilon_{f}\right)
\end{aligned}
$$

Since the four random variables $\alpha, \epsilon_{m}, \epsilon_{f}$ and $\eta\left(\tilde{\theta}, \theta_{m}\right)$ are independent and normally distributed, $w_{w}$ is itself also normally distributed with

$$
\begin{aligned}
& \text { mean }=\tau_{0}+\tau_{m} \phi e+\tau_{m}(1-\phi) e^{*}+\frac{\tau_{m}^{2} m\left(\tilde{\theta}, \theta_{m}\right)}{\lambda}+\tau_{f} e \text { and } \\
& \text { variance }=\tau_{m}^{2} \phi^{2} \sigma_{m}^{2}+\tau_{f}^{2} \sigma_{f}^{2}+\left(\tau_{m} \phi+\tau_{f}\right)^{2} \sigma_{\alpha}^{2}+\frac{\tau_{m}^{4}}{\lambda^{2}} \sigma^{2} .
\end{aligned}
$$

The expected utility of the worker is equal to

$$
\begin{aligned}
\mathbb{E}\left(v_{w}\right) & =\mathbb{E}\left(w_{w}-c(d(\theta, \tilde{\theta}), e)\right) \\
& =\tau_{0}+\tau_{m} \phi e+\tau_{m}(1-\phi) e^{*}+\frac{\tau_{m}^{2} m\left(\tilde{\theta}, \theta_{m}\right)}{\lambda}+\tau_{f} e-c(d(\theta, \tilde{\theta}), e)
\end{aligned}
$$


Once the constants are ruled out, we get that the worker simply maximizes:

$$
\begin{gathered}
\left(\phi \tau_{m}+\tau_{f}\right) e+\frac{\tau_{m}^{2}}{\lambda} m\left(\tilde{\theta}, \theta_{m}\right)-c(d(\theta, \tilde{\theta}), e)= \\
\left(\phi \tau_{m}+\tau_{f}\right) e+\frac{\tau_{m}^{2}}{\lambda}\left(1-\left(\tilde{\theta}-\theta_{m}\right)^{2}\right)-c(e)-(\tilde{\theta}-\theta)^{2}-c(e)(\tilde{\theta}-\theta)^{2}
\end{gathered}
$$

and from FOC we have:

(1) $\frac{\partial c}{\partial e}(d(\theta, \tilde{\theta}), e)=\phi \tau_{m}+\tau_{f}$

(2) $\frac{\partial c}{\partial d}(d(\theta, \tilde{\theta}), e) \frac{\partial d}{\partial \tilde{\theta}}(\theta, \tilde{\theta})=\frac{\tau_{m}^{2}}{\lambda} \frac{\partial m}{\partial \tilde{\theta}}\left(\tilde{\theta}, \theta_{m}\right)$

which leads to $c^{\prime}(e)=\frac{\phi \tau_{m}+\tau_{f}}{1+(\tilde{\theta}-\theta)^{2}}$ and $\tilde{\theta}=\frac{\frac{\tau_{m}^{2}}{\lambda} \theta_{m}+(1+c(e)) \theta}{\frac{\tau_{m}^{2}}{\lambda}+1+c(e)}$, i.e., to equations (14) and (15).

\section{Proof of equations (21), (22), (23) and (24)}

We have

$$
\begin{aligned}
w_{w}^{f n i}-w_{w}^{n f} & =\left(\tau_{0}+\tau_{m} \tilde{y}_{m}^{f n i}+\tau_{f} y_{f}\right)-\left(\tau_{0}+\tau_{m} \tilde{y}_{m}^{n f}+\tau_{f} y_{f}\right)=\tau_{m}\left(\tilde{y}_{m}^{f n i}-\tilde{y}_{m}^{n f}\right) \\
& =\tau_{m}\left(\phi y_{m}+(1-\phi) e^{*}+\frac{\tau_{m} \eta\left(\theta, \theta_{m}\right)}{\lambda}-\phi y_{m}-(1-\phi) e^{*}\right) \\
& =\frac{\tau_{m}^{2}}{\lambda} \eta\left(\theta, \theta_{m}\right)
\end{aligned}
$$

and hence, $\mathbb{E}\left(w_{w}^{f n i}-w_{w}^{n f}\right)=\frac{\tau_{m}^{2}}{\lambda} m\left(\theta, \theta_{m}\right) \geq 0$, i.e., we get $(21)$. Moreover,

$$
w_{m}^{f n i}-w_{m}^{n f}=\left(w_{0}-\frac{1}{2} \lambda\left(\tilde{y}_{m}^{f n i}-y_{f}\right)^{2}\right)-\left(w_{0}-\frac{1}{2} \lambda\left(\tilde{y}_{m}^{n f}-y_{f}\right)^{2}\right)
$$

Note that

$$
\begin{aligned}
\mathbb{E}\left(\left(\tilde{y}_{m}^{n f}-y_{f}\right)^{2}\right) & =\mathbb{E}\left(\left(\phi y_{m}+(1-\phi) e^{*}-y_{f}\right)^{2}\right) \\
& =\mathbb{E}\left(\left(\phi\left(y_{m}-y_{f}\right)+(1-\phi)\left(e^{*}-y_{f}\right)\right)^{2}\right) \\
& =\phi^{2} \mathbb{E}\left(\left(y_{m}-y_{f}\right)^{2}\right)+(1-\phi)^{2} \mathbb{E}\left(\left(e^{*}-y_{f}\right)^{2}\right)+2 \phi(1-\phi) \mathbb{E}\left(\left(y_{m}-y_{f}\right)\left(e^{*}-y_{f}\right)\right) \\
& =\phi^{2}\left(\sigma_{m}^{2}+\sigma_{f}^{2}\right)+(1-\phi)^{2}\left(\sigma_{\alpha}^{2}+\sigma_{f}^{2}\right)+2 \phi(1-\phi) \sigma_{f}^{2} \\
& =\phi^{2} \sigma_{m}^{2}+(1-\phi)^{2} \sigma_{\alpha}^{2}+\sigma_{f}^{2}=\phi \sigma_{m}^{2}+\sigma_{f}^{2}
\end{aligned}
$$

Therefore, by virtue of (13), we have

$$
\begin{aligned}
\mathbb{E}\left(w_{m}^{f n i}-w_{m}^{n f}\right) & =-\frac{1}{2} \lambda\left(\phi \sigma_{m}^{2}+\sigma_{f}^{2}+\frac{m\left(\theta, \theta_{m}\right)^{2} \tau_{m}^{2}}{\lambda^{2}}+\frac{\sigma^{2} \tau_{m}^{2}}{\lambda^{2}}\right)+\frac{1}{2} \lambda\left(\phi \sigma_{m}^{2}+\sigma_{f}^{2}\right) \\
& =-\frac{\tau_{m}^{2}}{2 \lambda}\left(m\left(\theta, \theta_{m}\right)^{2}+\sigma^{2}\right) \leq 0
\end{aligned}
$$

i.e., equation (22). Equation (23) follows from equations (8), (21) and (22). Furthermore, we get also equation (24), since

$$
\mathbb{E}\left(\pi^{f n i}\right)=\mathbb{E}\left(\pi^{n f}\right)-\mathbb{E}\left(w_{w}^{f n i}-w_{w}^{n f}+w_{m}^{f n i}-w_{m}^{n f}\right)=\mathbb{E}\left(\pi^{n f}\right)-\frac{\tau_{m}^{2}}{\lambda}\left(m\left(\theta, \theta_{m}\right)-\frac{m\left(\theta, \theta_{m}\right)^{2}}{2}-\frac{\sigma^{2}}{2}\right)
$$




\section{Proof of equations (26) and (27)}

We have

$$
\begin{gathered}
\tilde{y}_{m}^{f i}=\phi y_{m}^{f i}+(1-\phi) e^{f i}+\frac{\tau_{m}}{\lambda} \eta\left(\tilde{\theta}, \theta_{m}\right), \quad \tilde{y}_{m}^{f n i}=\phi y_{m}^{f n i}+(1-\phi) e^{f n i}+\frac{\tau_{m}}{\lambda} \eta\left(\theta, \theta_{m}\right) \\
y_{f}^{f i}=e^{f i}+\alpha+\epsilon_{f}^{f i}, \quad y_{f}^{f n i}=e^{f n i}+\alpha+\epsilon_{f}^{f n i} \\
w_{w}^{f i}-w_{w}^{f n i}=\left(\tau_{0}+\tau_{m} \tilde{y}_{m}^{f i}+\tau_{f} y_{f}^{f i}\right)-\left(\tau_{0}+\tau_{m} \tilde{y}_{m}^{f n i}+\tau_{f} y_{f}^{f n i}\right)
\end{gathered}
$$

and therefore

$$
\begin{aligned}
\mathbb{E}\left(w_{w}^{f i}-w_{w}^{f n i}\right) & =\tau_{m} \phi\left(\mathbb{E}\left(y_{m}^{f i}\right)-\mathbb{E}\left(y_{m}^{f n i}\right)\right)+\tau_{m}(1-\phi)\left(e^{f i}-e^{f n i}\right) \\
& +\frac{\tau_{m}^{2}}{\lambda}\left(m\left(\tilde{\theta}, \theta_{m}\right)-m\left(\theta, \theta_{m}\right)\right)+\tau_{f}\left(e^{f i}-e^{f n i}\right) \\
& =\tau_{m} \phi\left(e^{f i}-e^{f n i}\right)+\tau_{m}(1-\phi)\left(e^{f i}-e^{f n i}\right) \\
& +\frac{\tau_{m}^{2}}{\lambda}\left(m\left(\tilde{\theta}, \theta_{m}\right)-m\left(\theta, \theta_{m}\right)\right)+\tau_{f}\left(e^{f i}-e^{f n i}\right) \\
& =\left(\tau_{m}+\tau_{f}\right)\left(e^{f i}-e^{f n i}\right)+\frac{\tau_{m}^{2}}{\lambda}\left(m\left(\tilde{\theta}, \theta_{m}\right)-m\left(\theta, \theta_{m}\right)\right) \\
& =\left(\tau_{m}+\tau_{f}\right)\left(e^{f i}-e^{f n i}\right)+\frac{\tau_{m}^{2}}{\lambda}\left(\left(\theta-\theta_{m}\right)^{2}-\left(\tilde{\theta}-\theta_{m}\right)^{2}\right)
\end{aligned}
$$

which gives (26). Let $c(e)=\frac{1}{2} e^{2}$. Then from (20) and (25), we get

$$
e^{f i}=\frac{\phi \tau_{m}+\tau_{f}}{1+(\tilde{\theta}-\theta)^{2}}, \quad e^{f n i}=\phi \tau_{m}+\tau_{f}
$$

and therefore

$$
\begin{aligned}
\mathbb{E}\left(w_{w}^{f i}-w_{w}^{f n i}\right) & =\frac{\tau_{m}^{2}}{\lambda}\left(m\left(\tilde{\theta}, \theta_{m}\right)-m\left(\theta, \theta_{m}\right)\right)+\left(\tau_{m}+\tau_{f}\right)\left(e^{f i}-e^{f n i}\right) \\
& =\frac{\tau_{m}^{2}}{\lambda}\left(\left(\theta-\theta_{m}\right)^{2}-\left(\tilde{\theta}-\theta_{m}\right)^{2}\right)+\left(\tau_{m}+\tau_{f}\right)\left(\phi \tau_{m}+\tau_{f}\right)\left(\frac{1}{1+(\tilde{\theta}-\theta)^{2}}-1\right) \\
& =\frac{\tau_{m}^{2}}{\lambda}\left(\left(\theta-\theta_{m}\right)^{2}-\left(\tilde{\theta}-\theta_{m}\right)^{2}\right)-\left(\tau_{m}+\tau_{f}\right)\left(\phi \tau_{m}+\tau_{f}\right) \frac{(\tilde{\theta}-\theta)^{2}}{1+(\tilde{\theta}-\theta)^{2}}
\end{aligned}
$$

which gives (27).

\section{Proof of equations (29) and (30)}

Note that

$$
\tilde{y}_{m}^{f n i}-y_{f}^{f n i}=\frac{\tau_{m}}{\lambda} \eta\left(\theta, \theta_{m}\right)+\phi \epsilon_{m}^{f n i}-\epsilon_{f}^{f n i}-(1-\phi) \alpha
$$

and

$$
\tilde{y}_{m}^{f i}-y_{f}^{f i}=\frac{\tau_{m}}{\lambda} \eta\left(\tilde{\theta}, \theta_{m}\right)+\phi \epsilon_{m}^{f i}-\epsilon_{f}^{f i}-(1-\phi) \alpha
$$


Hence,

$$
\begin{aligned}
w_{m}^{f i}-w_{m}^{f n i} & =\left(w_{0}-\frac{1}{2} \lambda\left(\tilde{y}_{m}^{f i}-y_{f}^{f i}\right)^{2}\right)-\left(w_{0}-\frac{1}{2} \lambda\left(\tilde{y}_{m}^{f n i}-y_{f}^{f n i}\right)^{2}\right) \\
& =\frac{1}{2} \lambda\left[\left(\tilde{y}_{m}^{f n i}-y_{f}^{f n i}\right)^{2}-\left(\tilde{y}_{m}^{f i}-y_{f}^{f i}\right)^{2}\right] \\
& =\frac{1}{2} \lambda\left[\tau_{m}^{2} \frac{\eta\left(\theta, \theta_{m}\right)^{2}}{\lambda^{2}}+2 \frac{\tau_{m}}{\lambda} \eta\left(\theta, \theta_{m}\right)\left(\phi \epsilon_{m}^{f n i}-\epsilon_{f}^{f n i}-(1-\phi) \alpha\right)\right. \\
& +\left(\phi \epsilon_{m}^{f n i}-\epsilon_{f}^{f n i}-(1-\phi) \alpha\right)^{2}-\tau_{m}^{2} \frac{\eta\left(\tilde{\theta}, \theta_{m}\right)^{2}}{\lambda^{2}} \\
& \left.-2 \frac{\tau_{m}}{\lambda} \eta\left(\tilde{\theta}, \theta_{m}\right)\left(\phi \epsilon_{m}^{f i}-\epsilon_{f}^{f i}-(1-\phi) \alpha\right)+\left(\phi \epsilon_{m}^{f i}-\epsilon_{f}^{f i}-(1-\phi) \alpha\right)^{2}\right]
\end{aligned}
$$

Furthermore,

$$
\begin{aligned}
\mathbb{E}\left(w_{m}^{f i}-w_{m}^{f n i}\right) & =\frac{\tau_{m}^{2}}{2 \lambda}\left(\mathbb{E}\left(\eta\left(\theta, \theta_{m}\right)^{2}\right)-\mathbb{E}\left(\eta\left(\tilde{\theta}, \theta_{m}\right)^{2}\right)\right) \\
& =\frac{\tau_{m}^{2}}{2 \lambda}\left(m\left(\theta, \theta_{m}\right)^{2}+\sigma^{2}-m\left(\tilde{\theta}, \theta_{m}\right)^{2}-\sigma^{2}\right) \\
& =\frac{\tau_{m}^{2}}{2 \lambda}\left(m\left(\theta, \theta_{m}\right)-m\left(\tilde{\theta}, \theta_{m}\right)\right)\left(m\left(\theta, \theta_{m}\right)+m\left(\tilde{\theta}, \theta_{m}\right)\right) \\
& =\frac{\tau_{m}^{2}}{2 \lambda}\left(\left(\tilde{\theta}-\theta_{m}\right)^{2}-\left(\theta-\theta_{m}\right)^{2}\right)\left(2-\left(\tilde{\theta}-\theta_{m}\right)^{2}-\left(\theta-\theta_{m}\right)^{2}\right)
\end{aligned}
$$

which gives (29). Given that $\left(\tilde{\theta}-\theta_{m}\right)^{2}-\left(\theta-\theta_{m}\right)^{2}$ is always negative and $2-\left(\tilde{\theta}-\theta_{m}\right)^{2}-$ $\left(\theta-\theta_{m}\right)^{2}$ is always positive, we obtain $\mathbb{E}\left(w_{m}^{f i}-w_{m}^{f n i}\right) \leq 0$.

By virtue of equation (8), the variation of $v_{m}$ is equal to the sum of the variations of $w_{m}$ and $\eta(\tilde{\theta}, \theta) w_{w}$. The former is already given by (29). We now compute the latter variation.

$$
\begin{aligned}
\mathbb{E}\left(\eta(\tilde{\theta}, \theta) w_{w}^{f i}-\eta(\theta, \theta) w_{w}^{f n i}\right) & =m\left(\tilde{\theta}, \theta_{m}\right)\left(\tau_{0}+\left(\tau_{m}+\tau_{f}\right) e^{f i}\right)+\frac{\tau_{m}^{2}}{\lambda}\left(\sigma^{2}+m\left(\tilde{\theta}, \theta_{m}\right)^{2}\right) \\
& -m\left(\theta, \theta_{m}\right)\left(\tau_{0}+\left(\tau_{m}+\tau_{f}\right) e^{f n i}\right)-\frac{\tau_{m}^{2}}{\lambda}\left(\sigma^{2}+m\left(\theta, \theta_{m}\right)^{2}\right)
\end{aligned}
$$

Hence, we obtain:

$$
\begin{aligned}
\mathbb{E}\left(v_{m}^{f i}-v_{m}^{f n i}\right) & =\frac{\tau_{m}^{2}}{2 \lambda}\left(m\left(\theta, \theta_{m}\right)^{2}-m\left(\tilde{\theta}, \theta_{m}\right)^{2}\right)+\frac{\tau_{m}^{2}}{\lambda}\left(m\left(\tilde{\theta}, \theta_{m}\right)^{2}-m\left(\theta, \theta_{m}\right)^{2}\right) \\
& +m\left(\tilde{\theta}, \theta_{m}\right)\left(\tau_{0}+\left(\tau_{m}+\tau_{f}\right) e^{f i}\right)-m\left(\theta, \theta_{m}\right)\left(\tau_{0}+\left(\tau_{m}+\tau_{f}\right) e^{f n i}\right)
\end{aligned}
$$

which finally gives (30).

\section{Proof of equations (33) and (35)}

We have

$$
w_{w}^{f i \theta}-w_{w}^{f i}=\left(\tau_{0}+\tau_{m} \tilde{y}_{m}^{f i \theta}+\tau_{f} y_{f}^{f i \theta}\right)-\left(\tau_{0}+\tau_{m} \tilde{y}_{m}^{f i}+\tau_{f} y_{f}^{f i}\right)
$$


and the manager's report of the worker's performance is written as

$$
\tilde{y}_{m}^{f i \theta}=\phi y_{m}^{f i}+(1-\phi) e^{f i}+\frac{\eta\left(\bar{\theta}, \theta_{m}\right) \tau_{m}}{\lambda}
$$

Hence,

$$
\begin{aligned}
\mathbb{E}\left(w_{w}^{f i \theta}-w_{w}^{f i}\right) & =\tau_{m}\left(\tilde{y}_{m}^{f i \theta}-\tilde{y}_{m}^{f i}\right)=\frac{\tau_{m}^{2}}{\lambda}\left(m\left(\bar{\theta}, \theta_{m}\right)-m\left(\tilde{\theta}, \theta_{m}\right)\right)=\frac{\tau_{m}^{2}}{\lambda}\left(\left(\tilde{\theta}-\theta_{m}\right)^{2}-\left(\bar{\theta}-\theta_{m}\right)^{2}\right) \\
& =\frac{\tau_{m}^{2}}{\lambda}(\tilde{\theta}-\bar{\theta})\left(\tilde{\theta}+\bar{\theta}-2 \theta_{m}\right)
\end{aligned}
$$

We have

$$
\begin{gathered}
\tilde{\theta}-\bar{\theta}=\frac{\tau_{m}^{2}}{\lambda} \frac{\theta_{m}-\tilde{\theta}}{1+c\left(y_{m}^{f i}\right)} \\
\tilde{\theta}+\bar{\theta}-2 \theta_{m}=2 \tilde{\theta}+\frac{\tau_{m}^{2}}{\lambda} \frac{\tilde{\theta}-\theta_{m}}{1+c\left(y_{m}^{f i}\right)}-2 \theta_{m}=\left(\tilde{\theta}-\theta_{m}\right)\left(2+\frac{\tau_{m}^{2}}{\lambda} \frac{1}{1+c\left(y_{m}^{f i}\right)}\right)
\end{gathered}
$$

and by inserting these two expressions into $\mathbb{E}\left(w_{w}^{f i \theta}-w_{w}^{f i}\right)$, we finally get (33).

Furthermore,

$\mathbb{E}\left(w_{m}^{f i \theta}-w_{m}^{f i}\right)+\mathbb{E}\left(w_{w}^{f i \theta}-w_{w}^{f i}\right)=\frac{\tau_{m}^{2}}{2 \lambda}\left(m\left(\tilde{\theta}, \theta_{m}\right)^{2}-m\left(\bar{\theta}, \theta_{m}\right)^{2}\right)+\frac{\tau_{m}^{2}}{\lambda}\left(m\left(\bar{\theta}, \theta_{m}\right)-m\left(\tilde{\theta}, \theta_{m}\right)\right)$

By virtue of

$$
\mathbb{E}\left(\pi^{f i \theta}\right)=\mathbb{E}\left(\pi^{f i}\right)-\mathbb{E}\left(w_{m}^{f i \theta}-w_{m}^{f i}\right)-\mathbb{E}\left(w_{w}^{f i \theta}-w_{w}^{f i}\right)
$$

and the previous results, and using the definition of $m$ we get equation (35).

\section{Proof of equation (37)}

We have

$$
\begin{aligned}
L_{f w} & =\left(\tau_{0}+\tau_{m} \tilde{y}_{m}^{f i}+\tau_{f} y_{f}^{f i}\right)-\left(\tau_{0}+\tau_{m} \bar{y}_{m}+\tau_{f} y_{f}^{f i}\right)=\tau_{m}\left(\tilde{y}_{m}^{f i}-\bar{y}_{m}\right) \\
& =\frac{\tau_{m}}{\phi}\left(\frac{\tau_{m} m\left(\tilde{\theta}, \theta_{m}\right)}{\lambda}-(1-\phi)\left(\tilde{y}_{m}^{f i}-y_{f}^{f i}\right)\right) \\
& =\frac{\tau_{m}}{\phi}\left(\frac{\tau_{m} m\left(\tilde{\theta}, \theta_{m}\right)}{\lambda}-(1-\phi)\left(\phi y_{m}^{f i}+(1-\phi) e^{f i}+\frac{\tau_{m} \eta\left(\tilde{\theta}, \theta_{m}\right)}{\lambda}-y_{f}^{f i}\right)\right) \\
& =\frac{\tau_{m}}{\phi}\left(\frac{\tau_{m} m\left(\tilde{\theta}, \theta_{m}\right)}{\lambda}-(1-\phi)\left(\phi\left(y_{m}^{f i}-y_{f}^{f i}\right)+(1-\phi)\left(e^{f i}-y_{f}^{f i}\right)+\frac{\tau_{m} \eta\left(\tilde{\theta}, \theta_{m}\right)}{\lambda}\right)\right)
\end{aligned}
$$

and hence

$$
\mathbb{E}\left(L_{f w}\right)=\frac{\tau_{m}}{\phi}\left(\frac{\tau_{m} m\left(\tilde{\theta}, \theta_{m}\right)}{\lambda}-(1-\phi) \frac{\tau_{m} m\left(\tilde{\theta}, \theta_{m}\right)}{\lambda}\right)=\frac{\tau_{m}^{2} m\left(\tilde{\theta}, \theta_{m}\right)}{\lambda} \geq 0
$$




\section{Proof of equations (38) and (39)}

We have

$L_{f m}=\left(w_{0}-\frac{1}{2} \lambda\left(\tilde{y}_{m}^{f i}-y_{f}^{f i}\right)^{2}\right)-\left(w_{0}-\frac{1}{2} \lambda\left(\bar{y}_{m}-y_{f}^{f i}\right)^{2}\right)=\frac{\lambda}{2}\left(\left(\bar{y}_{m}-y_{f}^{f i}\right)^{2}-\left(\tilde{y}_{m}^{f i}-y_{f}^{f i}\right)^{2}\right)$

Let $b_{f}=\frac{\tau_{m} m\left(\tilde{\theta}, \theta_{m}\right)}{\lambda}$ be the bias estimated by the firm. As an intermediary step we first compute

$$
\begin{aligned}
\left(\bar{y}_{m}-y_{f}\right)^{2} & =\left(\tilde{y}_{m}^{f i}+\frac{1-\phi}{\phi}\left(\tilde{y}_{m}^{f i}-y_{f}^{f i}\right)-\frac{1}{\phi} b_{f}-y_{f}^{f i}\right)^{2} \\
& =\frac{1}{\phi^{2}}\left(\tilde{y}_{m}^{f i}-y_{f}^{f i}-b_{f}\right)^{2} \\
& =\frac{1}{\phi^{2}}\left(\left(\tilde{y}_{m}^{f i}-y_{f}^{f i}\right)^{2}+b_{f}^{2}-2 b_{f}\left(\tilde{y}_{m}^{f i}-y_{f}^{f i}\right)\right)
\end{aligned}
$$

Therefore, we have

$$
L_{f m}=\frac{\lambda}{2 \phi^{2}}\left(\left(1-\phi^{2}\right)\left(\tilde{y}_{m}^{f i}-y_{f}^{f i}\right)^{2}+b_{f}^{2}-2 b_{f}\left(\tilde{y}_{m}^{f i}-y_{f}^{f i}\right)\right)
$$

and

$$
\mathbb{E}\left(L_{f m}\right)=\frac{\lambda}{2 \phi^{2}}\left(\left(1-\phi^{2}\right) \mathbb{E}\left(\left(\tilde{y}_{m}^{f i}-y_{f}^{f i}\right)^{2}\right)+b_{f}^{2}-2 b_{f} \mathbb{E}\left(\tilde{y}_{m}^{f i}-y_{f}^{f i}\right)\right)
$$

Moreover, by equations (3) and (13) we have

$$
\mathbb{E}\left(\left(\tilde{y}_{m}^{f i}-y_{f}^{f i}\right)^{2}\right)=\phi \sigma_{m}^{2}+\sigma_{f}^{2}+\frac{m\left(\tilde{\theta}, \theta_{m}\right)^{2} \tau_{m}^{2}}{\lambda^{2}}+\frac{\sigma^{2} \tau_{m}^{2}}{\lambda^{2}}
$$

and from equation (12)

$$
b_{f}^{2}=\frac{m\left(\tilde{\theta}, \theta_{m}\right)^{2} \tau_{m}^{2}}{\lambda^{2}}
$$

Hence, we get:

$$
\mathbb{E}\left(\tilde{y}_{m}^{f i}-y_{f}^{f i}\right)=\mathbb{E}\left(\phi y_{m}^{f i}+(1-\phi) e^{f i}+\frac{\tau_{m} \eta\left(\tilde{\theta}, \theta_{m}\right)}{\lambda}-y_{f}^{f i}\right)=\frac{\tau_{m} m\left(\tilde{\theta}, \theta_{m}\right)}{\lambda}=b_{f}
$$

Combining the previous equalities, we get

$$
\begin{aligned}
\mathbb{E}\left(L_{f m}\right) & =\frac{\lambda}{2 \phi^{2}}\left[\left(1-\phi^{2}\right) \mathbb{E}\left(\left(\tilde{y}_{m}^{f i}-y_{f}^{f i}\right)^{2}\right)-b_{f}^{2}\right] \\
& =\frac{\lambda}{2 \phi^{2}}\left[\left(1-\phi^{2}\right)\left(\phi \sigma_{m}^{2}+\sigma_{f}^{2}+\frac{m\left(\tilde{\theta}, \theta_{m}\right)^{2} \tau_{m}^{2}}{\lambda^{2}}+\frac{\sigma^{2} \tau_{m}^{2}}{\lambda^{2}}\right)-\frac{m\left(\tilde{\theta}, \theta_{m}\right)^{2} \tau_{m}^{2}}{\lambda^{2}}\right] \\
& =\frac{\lambda\left(1-\phi^{2}\right)}{2 \phi^{2}}\left(\phi \sigma_{m}^{2}+\sigma_{f}^{2}+\frac{\sigma^{2} \tau_{m}^{2}}{\lambda^{2}}\right)-\frac{\tau_{m}^{2}}{2 \lambda} m\left(\tilde{\theta}, \theta_{m}\right)^{2}
\end{aligned}
$$


which gives (38). Finally, the expected aggregate loss of the firm is given by

$$
\begin{aligned}
\mathbb{E}\left(L_{f}\right) & =\mathbb{E}\left(L_{f w}\right)+\mathbb{E}\left(L_{f m}\right) \\
& =\frac{\lambda\left(1-\phi^{2}\right)}{2 \phi^{2}}\left(\phi \sigma_{m}^{2}+\sigma_{f}^{2}+\frac{\sigma^{2} \tau_{m}^{2}}{\lambda^{2}}\right)+\frac{\tau_{m}^{2} m\left(\tilde{\theta}, \theta_{m}\right)}{\lambda}-\frac{\tau_{m}^{2}}{2 \lambda} m\left(\tilde{\theta}, \theta_{m}\right)^{2} \\
& =\frac{\lambda\left(1-\phi^{2}\right)}{2 \phi^{2}}\left(\phi \sigma_{m}^{2}+\sigma_{f}^{2}+\frac{\sigma^{2} \tau_{m}^{2}}{\lambda^{2}}\right)+\frac{\tau_{m}^{2} m\left(\tilde{\theta}, \theta_{m}\right)}{\lambda}\left(1-\frac{1}{2} m\left(\tilde{\theta}, \theta_{m}\right)\right) \geq 0
\end{aligned}
$$

as given in (39).

\section{Proof of equations (40) and (41)}

Let $\tilde{y}_{m}^{f i 2}$ denote the manager's report of the worker's performance in the case when the manager tries to infer the real opinion and the firm tries to infer the real observation of the performance. Let $\hat{y}_{m}$ denote the firm's estimation of the manager's observation of the worker's performance in this case. We have

$$
\begin{gathered}
\tilde{y}_{m}^{f i 2}=\phi \hat{y}_{m}+(1-\phi) y_{f}^{f i}+\frac{m\left(\bar{\theta}, \theta_{m}\right) \tau_{m}}{\lambda} \\
\hat{y}_{m}=\tilde{y}_{m}^{f i 2}+\frac{1-\phi}{\phi}\left(\tilde{y}_{m}^{f i 2}-y_{f}^{f i}\right)-\frac{\tau_{m} m\left(\bar{\theta}, \theta_{m}\right)}{\phi \lambda}
\end{gathered}
$$

and the firm's loss with respect to the worker's wage is given by

$$
\begin{aligned}
\hat{L}_{f w} & =\left(\tau_{0}+\tau_{m} \tilde{y}_{m}^{f i 2}+\tau_{f} y_{f}^{f i}\right)-\left(\tau_{0}+\tau_{m} \hat{y}_{m}+\tau_{f} y_{f}^{f i}\right)=\tau_{m}\left(\tilde{y}_{m}^{f i 2}-\hat{y}_{m}\right) \\
& =\frac{\tau_{m}}{\phi}\left(\frac{\tau_{m} m\left(\bar{\theta}, \theta_{m}\right)}{\lambda}-(1-\phi)\left(\tilde{y}_{m}^{f i 2}-y_{f}^{f i}\right)\right) \\
& =\frac{\tau_{m}}{\phi}\left(\frac{\tau_{m} m\left(\bar{\theta}, \theta_{m}\right)}{\lambda}-(1-\phi)\left(\phi y_{m}^{f i}+(1-\phi) e^{f i}+\frac{\tau_{m} \eta\left(\bar{\theta}, \theta_{m}\right)}{\lambda}-y_{f}^{f i}\right)\right) \\
& =\frac{\tau_{m}}{\phi}\left(\frac{\tau_{m} m\left(\bar{\theta}, \theta_{m}\right)}{\lambda}-(1-\phi)\left(\phi\left(y_{m}^{f i}-y_{f}^{f i}\right)+(1-\phi)\left(e^{f i}-y_{f}^{f i}\right)+\frac{\tau_{m} \eta\left(\bar{\theta}, \theta_{m}\right)}{\lambda}\right)\right)
\end{aligned}
$$

and hence the expected loss of the firm is equal to

$$
\mathbb{E}\left(\hat{L}_{f w}\right)=\frac{\tau_{m}}{\phi}\left(\frac{\tau_{m} m\left(\bar{\theta}, \theta_{m}\right)}{\lambda}-(1-\phi) \frac{\tau_{m} m\left(\bar{\theta}, \theta_{m}\right)}{\lambda}\right)=\frac{\tau_{m}^{2}}{\lambda} m\left(\bar{\theta}, \theta_{m}\right) \geq 0
$$

which gives (40). Furthermore, when comparing the losses, we get

$$
\mathbb{E}\left(\hat{L}_{f w}\right)-\mathbb{E}\left(L_{f w}\right)=\frac{\tau_{m}^{2}}{\lambda}\left(m\left(\bar{\theta}, \theta_{m}\right)-m\left(\tilde{\theta}, \theta_{m}\right)\right)=\frac{\tau_{m}^{2}}{\lambda}\left(\left(\tilde{\theta}-\theta_{m}\right)^{2}-\left(\bar{\theta}-\theta_{m}\right)^{2}\right) \leq 0
$$

that is, we have (41). Proving that

$$
\left(\left(\tilde{\theta}-\theta_{m}\right)^{2}-\left(\bar{\theta}-\theta_{m}\right)^{2}\right) \leq 0
$$

relies on equations (15) and (32). We consider the following two cases: 
- Case 1: $\theta \leq \theta_{m}$

Then, $\theta \leq \tilde{\theta} \leq \theta_{m}$. Moreover, we get $\bar{\theta} \leq \tilde{\theta}$ and therefore $\bar{\theta} \leq \tilde{\theta} \leq \theta_{m}$. Hence, $\bar{\theta}-\theta_{m} \leq \tilde{\theta}-\theta_{m} \leq 0$ and finally $\left(\bar{\theta}-\theta_{m}\right)^{2} \geq\left(\tilde{\theta}-\theta_{m}\right)^{2}$.

- Case 2: $\theta \geq \theta_{m}$

Then, $\theta \geq \tilde{\theta} \geq \theta_{m}$. Moreover, we get $\bar{\theta} \geq \tilde{\theta}$ and therefore $\bar{\theta} \geq \tilde{\theta} \geq \theta_{m}$. Hence, $\bar{\theta}-\theta_{m} \geq \overline{\tilde{\theta}}-\theta_{m} \geq 0$ and finally $\left(\bar{\theta}-\theta_{m}\right)^{2} \geq\left(\tilde{\theta}-\theta_{m}\right)^{2}$.

\section{Proof of equations (42) and (43)}

We have

$\hat{L}_{f m}=\left(w_{0}-\frac{1}{2} \lambda\left(\tilde{y}_{m}^{f i 2}-y_{f}^{f i}\right)^{2}\right)-\left(w_{0}-\frac{1}{2} \lambda\left(\hat{y}_{m}-y_{f}^{f i}\right)^{2}\right)=\frac{1}{2} \lambda\left(\left(\hat{y}_{m}-y_{f}^{f i}\right)^{2}-\left(\tilde{y}_{m}^{f i 2}-y_{f}^{f i}\right)^{2}\right)$

and therefore

$$
\mathbb{E}\left(\hat{L}_{f m}\right)=\frac{\lambda\left(1-\phi^{2}\right)}{2 \phi^{2}}\left(\phi \sigma_{m}^{2}+\sigma_{f}^{2}+\frac{\sigma^{2} \tau_{m}^{2}}{\lambda^{2}}\right)-\frac{\tau_{m}^{2}}{2 \lambda} m\left(\bar{\theta}, \theta_{m}\right)^{2}
$$

as stated in (42). Furthermore,

$$
\begin{aligned}
\mathbb{E}\left(\hat{L}_{f m}\right)-\mathbb{E}\left(L_{f m}\right) & =\frac{\tau_{m}^{2}}{2 \lambda}\left(m\left(\tilde{\theta}, \theta_{m}\right)^{2}-m\left(\bar{\theta}, \theta_{m}\right)^{2}\right) \\
& =\frac{\tau_{m}^{2}}{2 \lambda}\left[\left(1-\left(\tilde{\theta}-\theta_{m}\right)^{2}\right)^{2}-\left(1-\left(\bar{\theta}-\theta_{m}\right)^{2}\right)^{2}\right] \\
& =\frac{\tau_{m}^{2}}{2 \lambda}\left(\left(\bar{\theta}-\theta_{m}\right)^{2}-\left(\tilde{\theta}-\theta_{m}\right)^{2}\right)\left(2-\left(\bar{\theta}-\theta_{m}\right)^{2}-\left(\tilde{\theta}-\theta_{m}\right)^{2}\right) \geq 0
\end{aligned}
$$

which gives (43). The last inequality comes from the fact that $\left(\bar{\theta}-\theta_{m}\right)^{2}+\left(\tilde{\theta}-\theta_{m}\right)^{2} \leq 2$ and that $\left(\left(\bar{\theta}-\theta_{m}\right)^{2}-\left(\tilde{\theta}-\theta_{m}\right)^{2}\right) \geq 0$ as shown above.

\section{Proof of equations (44) and (45)}

We have

$$
\begin{aligned}
\mathbb{E}\left(\hat{L}_{f}\right) & =\mathbb{E}\left(\hat{L}_{f w}\right)+\mathbb{E}\left(\hat{L}_{f m}\right) \\
& =\frac{\lambda\left(1-\phi^{2}\right)}{2 \phi^{2}}\left(\phi \sigma_{m}^{2}+\sigma_{f}^{2}+\frac{\sigma^{2} \tau_{m}^{2}}{\lambda^{2}}\right)-\frac{\tau_{m}^{2}}{2 \lambda} m\left(\bar{\theta}, \theta_{m}\right)^{2}+\frac{\tau_{m}^{2}}{\lambda} m\left(\bar{\theta}, \theta_{m}\right) \geq 0
\end{aligned}
$$

since

$$
\frac{\lambda\left(1-\phi^{2}\right)}{2 \phi^{2}}\left(\phi \sigma_{m}^{2}+\sigma_{f}^{2}+\frac{\sigma^{2} \tau_{m}^{2}}{\lambda^{2}}\right) \geq 0
$$

and

Finally,

$$
-\frac{\tau_{m}^{2}}{2 \lambda} m\left(\bar{\theta}, \theta_{m}\right)^{2}+\frac{\tau_{m}^{2}}{\lambda} m\left(\bar{\theta}, \theta_{m}\right)=\frac{\tau_{m}^{2}}{\lambda}\left(m\left(\bar{\theta}, \theta_{m}\right)-m\left(\bar{\theta}, \theta_{m}\right)^{2} / 2\right) \geq 0
$$

$$
\begin{aligned}
\mathbb{E}\left(\hat{L}_{f}\right)-\mathbb{E}\left(L_{f}\right) & =\frac{\tau_{m}^{2}}{\lambda}\left(m\left(\bar{\theta}, \theta_{m}\right)-m\left(\tilde{\theta}, \theta_{m}\right)\right)+\frac{\tau_{m}^{2}}{2 \lambda}\left(m\left(\tilde{\theta}, \theta_{m}\right)^{2}-m\left(\bar{\theta}, \theta_{m}\right)^{2}\right) \\
& =\frac{\tau_{m}^{2}}{\lambda}\left(m\left(\bar{\theta}, \theta_{m}\right)-m\left(\tilde{\theta}, \theta_{m}\right)\right)\left(1-\frac{1}{2}\left(m\left(\bar{\theta}, \theta_{m}\right)+m\left(\tilde{\theta}, \theta_{m}\right)\right)\right) \leq 0
\end{aligned}
$$

which completes the proof. 


\section{Bibliography}

G. A. Akerlof. A theory of social custom, of which unemployment may be one consequence. The Quarterly Journal of Economics, 94:749-775, 1980.

S. H. Appelbaum and B. Hughes. Ingratiation as a political tactic: Effects within the organization. Management Decision, 36(2):85-95, 1998.

S. Asch. Effects of group pressure upon the modification and distortion of judgments. In H. Guetzkow, editor, Groups, Leadership and Men Research in Human Relations, pages 177-190. Pittsburgh: Carnegie Press, 1951.

G. P. Baker. Incentive contracts and performance measurement. Journal of Political Economy, 100:598-614, 1992.

O. Bandiera, I. Barankai, and I. Rasul. Social connections and incentives in the workplace: Evidence from personnel data. Econometrica, 77(4):1047-1094, 2009.

A. V. Banerjee. A simple model of herd behavior. Quarterly Journal of Economics, 107(3):797-817, 1992.

B. D. Bernheim. A theory of conformity. Journal of Political Economy, 102(5):841-877, 1994.

S. Bikhchandani, D. Hirshleifer, and I. Welch. A theory of fads, fashion, custom, and cultural change as informational cascades. Journal of Political Economy, 100:992-1026, 1992.

Y. Bramoullé and S. Goyal. Favoritism. Working Paper, Aix-Marseille University and University of Cambridge, 2014.

J. Brandts and C. Sola. Personal relations and their effect on behavior in an organizational setting: and experimental study. Journal of Economic Behavior and Organization, 73: 246-253, 2010.

C. Efferson, R. Lalive, and E. Fehr. The coevolution of cultural groups and ingroup favoritism. Science, 321, 2008.

A. Falk and C. Zehnder. A city-wide experiment on trust discrimination. Journal of Public Economics, 100:15-27, 2013.

A. Filippin and F. Guala. Costless discrimination and unequal achievements in a labour market tournament. Experimental Economics, 16(3):285-305, 2013.

J. Gardner. Executive Masters in Leadership - Capstone Project. Georgetown University, McDonough School of Business, 2011.

L. Garicano, I. Palacios, and C. Prendergast. Favoritism under social pressure. Review of Economics and Statistics, 87:208-216, 2005.

C. Goldin and C. Rouse. Orchestrating impartiality: the impact of "blind" auditions on female musicians. American Economic Review, 94(4):715-741, 2000.

R. A. Gordon. Impact of ingratiation on judgments and evaluation: A meta-analytic investigation. Journal of Personality and Social Psychology, 71, 1996.

C. A. Higgins, T. A. Judge, and G. R. Ferris. Influence tactics and work outcomes: A meta-analysis. Journal of Organizational Behavior, 24:89-106, 2003.

B. Holmstrom and P. R. Milgrom. Multitask principal-agent analyses: Incentive contracts, asset ownership, and job design. Journal of Law, Economics and Organization, 7:24-52, 1991.

E. E. Jones. Ingratiation. New-York: Appleton-Century-Crofts, 1964. 
S. R. G. Jones. The Economics of Conformism. Oxford: Blackwell, 1984.

J. Knowles, N. Persico, and P. Todd. Racial bias in motor vehicle searches: theory and evidence. Journal of Political Economy, 109(1):203-229, 2001.

M. Kocher and M. Sutter. Favoritism of agents - The case of referees' home bias. Journal of Economic Psychology, 25:461-469, 2004.

F. Kofman and J. Lawarrée. Collusion in hierarchical agency. Econometrica, 61:629-656, 1993.

D. N. Laband and M. J. Piette. Favoritism versus search for good papers: Empirical evidence regarding the behavior of journal editors. Journal of Political Economy, 102(1): 194-203, 1994.

D. K. Levine, F. Weinschelbaum, and F. Zurita. The brother in law effect. International Economic Review, 51:497-507, 2010.

R. C. Liden and T. R. Mitchell. Ingratiatory behaviors in organizational settings. Academy of Management Review, 13:572-587, 1988.

P. R. Milgrom. Employment contracts, influence activities, and efficient organization design. Journal of Political Economy, 96:42-60, 1988.

P. R. Milgrom and D. J. Roberts. An economic approach to influence activities in organizations. American Journal of Sociology, 94:154-179, 1988.

P. R. Milgrom and D. J. Roberts. The efficiency of equity in organizational decision processes. American Economic Review. Papers and Proceedings, 80:154-159, 1990.

J. M. Podolny and J. N. Baron. Resources and relationships: Social networks and mobility in the workplace. American Sociological Review, 62:673-693, 1997.

C. Prendergast. A theory of "yes men". American Economic Review, 83(4):757-770, 1993.

C. Prendergast and R. H. Topel. Favoritism in organizations. Journal of Political Economy, 104(5):958-978, 1996.

S. Robin, A. Rusinowska, and M.-C. Villeval. Ingratiation: Experimental evidence. European Economic Review, 66:16-38, 2014.

D. Scharfstein and J. Stein. Herd behavior and investment. American Economic Review, 80:465-479, 1990.

D. A. Thomas. The impact of race on managers' experiences of developmental relationships. Journal of Organizational Behavior, 11:479-492, 1990.

J. Tirole. Hierarchies and bureaucracies: On the role of collusion in organizations. Journal of Law, Economics and Organization, 2:181-214, 1986.

G. M. Vaughan and H. A. Hogg. Introduction to Social Psychology. French Forest NSW, Australia: Pearson Education, 2008.

M. A. Wesolowski and K. W. Mossholder. Relational demography in supervisorsubordinate dyads: Impact on subordinate job satisfaction, burnout, and perceived procedural justice. Journal of Organizational Behavior, 18:351-362, 1997.

J. D. Westphal and I. Stern. The other pathway to the boardroom: Interpersonal influence behavior as a substitute for elite credentials and majority status in obtaining board appointments. Administrative Science Quarterly, 51:169-204, 2006.

C. B. Wortman and J. A. W. Linsenmeier. Interpersonal attraction and techniques of ingratiation in organizational settings. In B. W. Staw and G. R. Salancik, editors, New Directions in Organizational Behavior, pages 133-178. St Clair, Chicago, 1977.

D. J. Zizzo. You are not in my boat: common fate and discrimination against outgroup members. International Review of Economics, 58:91-103, 2011. 